\title{
LA PRESCRIPCIÓN EXTINTIVA \\ EN EL CONTRATO DE SEGURO: UNA APROXIMACIÓN A SU INCIDENCIA Y CONFIGURACIÓN EN EL ORDENAMIENTO JURÍDICO COLOMBIANO
}

\author{
THE STATUTE OF LIMITATIONS \\ IN THE INSURANCE CONTRACT: AN APPROXIMATION \\ TO ITS INCIDENCE AND CONFIGURATION IN THE \\ COLOMBIAN LEGAL SYSTEM
}

JUAN CAMILO BEDOYA CHAVARRIAGA*

Fecha de recepción: 8 de agosto de 2020

Fecha de aceptación: 20 de noviembre de 2020

Disponible en línea: 30 de diciembre de 2020

Para citar este artículo/To cite this article

Bedoya Chavarriaga, Juan Camilo, La prescripción extintiva en el contrato de seguro: una aproximación a su incidencia y configuración en el ordenamiento jurídico colombiano, 53 Rev. Ibero-Latinoam.Seguros, 181-222 (2020). https://doi.org/10.11144/Javeriana.ris53.pecs

doi:10.11144/Javeriana.ris53.pecs

\footnotetext{
* Abogado y Magister en Derecho de la Universidad Nacional de Colombia. Estudiante de la especialización en Derecho de Seguros de la Pontificia Universidad Javeriana. Miembro de la Red de Arbitraje Juvenil de la Cámara de Comercio de Bogotá, así como de diversos grupos de investigación de la Universidad Nacional de Colombia. Actualmente se desempeña como abogado en la firma Vivas \& Uribe Abogados S.A.S. ORCID: 0000-0001-8176-9900. E-Mail: bedoyajuan@javeriana.edu.co - jucbedoyach@unal.edu.co.
} 


\section{RESUMEN}

La prescripción extintiva constituye un tema central de estudio en relación con el contrato de seguro al delimitar temporalmente el derecho del beneficiario a presentar una reclamación ante la compañía aseguradora una vez ocurrido el siniestro, así como, al tenor de lo dispuesto en el art. 1081 del Código de Comercio, el ejercicio en cabeza de las partes del negocio jurídico de los derechos y acciones derivados de aquel y las normas que regulan su celebración y ejecución. De allí que, el presente trabajo, pretenda abordar de forma sintética las disposiciones normativas y pautas jurisprudenciales que regulan, bajo el ordenamiento jurídico colombiano, la aplicación de la institución de la prescripción al contrato de seguro y las acciones derivadas de las normas que lo regulan para de esta manera dilucidar la forma en que aplica la prescripción y sus particularidades en algunos procesos.

Palabras Claves: Derecho de Seguros, Prescripción Extintiva, Suspensión, Interrupción.

\section{ABSTRACT}

The statute of limitation is a central topic of study in relation to the insurance contract as it temporarily delimits the right of the beneficiary to lodge a claim to the insurance company after the occurrence of the sinister, as well as, under article 1081 of the Commercial Code, the exercise of the rights and actions in head of the parts of the contract and the rules governing its celebration and execution. Hence, the present work seeks to address in a synthesized way the normative provisions and jurisprudential guidelines that regulate, under the Colombian legal system, the application of the institution of the extinctive prescription to the insurance contract and the actions deriving from the rules governing it in order to elucidate the way in which the limitation period applies and the particularities that it possesses within certain processes and contracts.

Key Words: Insurance Law, Statute of Limitation, Suspension, Interruption. 


\section{INTRODUCCIÓN}

La prescripción, en tanto forma de extinguir las obligaciones, reviste una importancia trascendental en materia de derecho de seguros al delimitar temporalmente el derecho a exigir de la aseguradora la indemnización causada con ocasión de la ocurrencia o configuración de un riesgo amparado bajo la póliza de seguro. De igual forma, este instituto normativo resulta igualmente aplicable al régimen temporal para el ejercicio de las acciones derivadas del contrato y las normas que rigen el mismo, siendo tal el caso de la subrogación y de la nulidad por declaración no sincera del estado del riesgo, en la medida en que la totalidad de las acciones y excepciones ligadas con el paso del tiempo en materia de derecho de seguros se encuentran, íntimamente relacionadas con el fenómeno prescriptivo.

De allí que el presente trabajo pretenda abordar de forma más o menos sucinta el alcance y aplicación de la institución jurídica de la prescripción extintiva al contrato de seguro, analizando en el proceso las variaciones que la ley introdujo en relación con su cómputo frente a la legislación general establecida en el Código Civil, así como las modificaciones que en relación con las disposiciones normativas consignadas por el legislador en los arts. 1081 y 1131 del Código de Comercio han sido introducidas a través del ejercicio judicial y arbitral.

En línea con lo expuesto, el presente trabajo se estructura en tres acápites a través de los cuales se busca abordar la aplicación de la prescripción al contrato de seguros y las acciones derivadas de las leyes que lo rigen, partiendo para ello en el capítulo primero, titulado "Aproximación al concepto de prescripción y su aplicación en materia de seguros", de una revisión del concepto y naturaleza de la prescripción tal y como se encuentra delimitada en las leyes constitutivas del Código Civil, para a punto seguido, analizar el establecimiento específico de una regulación para la prescripción en materia de seguros en el art. 1081 del Código de Comercio, así como la delimitación en el art. 1131 del mismo cuerpo normativo aplicable a las acciones derivadas del contrato de seguro de responsabilidad civil, concluyendo el acápite en cuestión con la revisión a la aplicación de la suspensión e interrupción del cómputo de la prescripción regulada en los artículos señalados.

Por su parte, el capítulo segundo denominado "Consideraciones adicionales entorno a la configuración y cómputo de la prescripción en el contrato de seguro" busca profundizar en la aplicación de la prescripción establecida en los arts. 1081 y 1131 del Código de Comercio, partiendo para ello de analizar la forma en que opera dicho instituto jurídico en los seguros pactados bajo la delimitación temporal claims made o "por descubrimiento", para a punto seguido realizar algunas breves consideraciones en relación con la posibilidad de renunciar a la prescripción, y analizar a continuación la prescripción de la acción de nulidad relativa derivada de la declaración reticente del estado del riesgo, concluyendo de esta forma con una revisión al cómputo de la prescripción entorno a la subrogación en materia del contrato de seguro.

Finalmente, el capítulo tercero titulado "Aproximación a otros aspectos relevantes de la prescripción en materia de seguros" se ocupa en analizar en primera medida la 
norma especial para el cómputo de la prescripción al interior de los procesos de responsabilidad fiscal, para a continuación realizar una breve aproximación al fenómeno de la prescripción en materia del seguro previsional, concluyendo con un análisis de la prescripción especial dispuesta por el legislador en relación con la acción de protección al consumidor.

\title{
1. APROXIMACIÓN AL CONCEPTO DE PRESCRIPCIÓN Y SU APLICACIÓN EN MATERIA DE SEGUROS
}

\subsection{Concepto y naturaleza de la prescripción}

\author{
Conforme a lo dispuesto en el art. 2512 del Código Civil
}

"La prescripción es un modo de adquirir las cosas ajenas, o de extinguir las acciones o derechos ajenos, por haberse poseído las cosas y no haberse ejercido dichas acciones y derechos durante cierto lapso de tiempo, y concurriendo los demás requisitos legales”.

De allí que la misma se clasifique, según se circunscriba al campo de los derechos reales o los personales, en prescripción adquisitiva o usucapión y prescripción extintiva o liberatoria ${ }^{1}$, siendo de interés para el asunto que nos ocupa únicamente la prescripción extintiva en relación con la cual señala el art. 2535 del Código Civil, lo siguiente: "La prescripción que extingue las acciones y derechos ajenos exige solamente cierto lapso de tiempo durante el cual no se hayan ejercicio dichas acciones. Se cuenta este tiempo desde que la obligación se haya hecho exigible".

Ahora bien, la prescripción en tanto instituto jurídico se justifica en la medida que consolida determinadas situaciones por el simple paso del tiempo garantizando en el proceso la seguridad jurídica y el interés público toda vez que “(...) ningún beneficio representa para la sociedad que, como se anticipó, las relaciones jurídicas se mantengan insolubles, eterna o indefinidamente"2. Lo anterior, resulta aún más claro si se toma en consideración que tal y como lo ha manifestado la Corte Constitucional:

\begin{abstract}
"Ha sido universalmente aceptado que la causa que justifica el instituto de la prescripción de la acción, es sin duda, la seguridad jurídica y el orden público, pues el interés general de la sociedad exige que haya certeza y estabilidad en las relaciones jurídicas. Sin embargo, también se afirma que es la lógica consecuencia de la negligencia o inactividad de quien debe hacerla valer oportunamente, esto es, dentro del tiempo y condiciones que consagre la ley, porque las acciones duran mientras el derecho a la tutela jurídica no haya perecido y ese derecho, generalmente, subsiste en tanto y en cuanto no se haya perdido por la inactividad del titular"3.
\end{abstract}

\footnotetext{
1 Bonivento Jiménez, José Armando. Obligaciones. Ed. Legis. (2017), p. 477. y Castro, José Fernando; Calonje Londoño, J. \& Nataly Ximena. Derecho de obligaciones: Aproximación a la praxis y a la constitucionalización. Ed. Universidad Católica de Colombia. (2015), pp. 245-246.

2 Corte Suprema de Justicia. Sala de Casación Civil. Proceso 4690 (M.P. Carlos Ignacio Jaramillo Jaramillo; junio 29 de 2007).

3 Corte Constitucional de Colombia. Sentencia T-658 de 1998 (M.P. Carlos Gaviria Díaz: noviembre 11 de 1998) y en Bonivento Jiménez, José Armando. Obligaciones, pp. 477-478. Ed. Legis. (2017).
} 
Vista la justificación de la existencia de la prescripción, resulta pertinente abordar los requisitos para su configuración; a saber: 1) Que el derecho o la acción no sean imprescriptibles conforme a la ley, tal y como es el caso de los bienes de los cuales trata el art. 63 Constitucional $^{4}$; 2) Que se presenta una inacción por parte del acreedor; 3) Que transcurra el lapso determinado por la ley para su configuración; y 4) Que se solicite su declaración al juez conforme a lo dispuesto en el art. 2513 del Código Civil y demás disposiciones concordantes ${ }^{5}$.

Entre los requisitos enunciados, tal vez el que reviste una mayor importancia para la comprensión de la institución de la prescripción es el paso del tiempo, en la medida que delimita la inacción del acreedor necesaria para su configuración y, por lo tanto, para la consolidación de las relaciones entre los asociados al interior del ordenamiento normativo. Ahora bien, según el tiempo necesario para su configuración, la prescripción extintiva podrá clasificarse en corta o $\operatorname{larga}^{6}$, siendo la regla general para el inicio de su cómputo, la exigibilidad de la obligación, es decir la establecida en el art. 2536 del Código Civil, en cuya literalidad dispuso el legislador:

"La acción ejecutiva se prescribe por cinco (5) años y la ordinaria por diez (10). La acción ejecutiva se convierte en ordinaria por el lapso de cinco (5) años, y convertida en ordinaria durará solamente otros cinco (5). Una vez interrumpida o renunciada una prescripción, comenzará a contarse nuevamente el respectivo término".

En relación con el particular, ha sostenido el Dr. José Armando BonIVENTo JiMÉNEZ, lo siguiente:

"La dualidad expresada de cinco y diez años para la prescripción de la acción ejecutiva y la declarativa, respectivamente, sirve para apuntalar la afirmación de que son separables, conceptualmente hablando, la prescripción de la acción y la del derecho como tal, lo que se hace evidente cuando se advierte que a los cinco años de inactividad del acreedor prescribe la acción ejecutiva, sin afectación como total (sic) de la existencia y vigencia del crédito, que podrá ser reclamado judicialmente, sólo que ya por la vía de la acción declarativa, dentro del período de cinco años más-corresponde a los diez años de prescripción de dicha acción-, lo que no obsta para señalar que transcurridos 10 años, contados a partir de la exigibilidad de la obligación, sin que el tiempo de prescripción hubiere sido interrumpido, esa prescripción lo será de la

\footnotetext{
${ }^{4}$ Frente al particular sostiene el Dr. Fernando HinesTrosa: "Siendo la regla general la de la extinguibilidad de las acciones y de los derechos subjetivos por prescripción, parejamente en todos los ordenamientos siempre ha habido un sector reservado, inmune a los efectos consuntivos de la inercia del titular frente al paso del tiempo: el de la relación jurídico familiar que no esté enderezada al establecimiento hacia el futuro de un estado correspondiente a ella, el de los derechos indisponibles y los demás derechos indicados en la ley, como prevé el artículo 2934 del Código Civil italiano; en principio, los derechos extrapatrimoniales son imprescriptibles. Por regla general, todo derecho y toda acción son susceptibles de extinguirse por medio de la prescripción. Sin embargo, no se debe perder de vista que, así sea en número reducido, hay derechos y pretensiones inmunes a la prescripción, es decir, que escapan al efecto nocivo del tiempo, o dicho sin más, que son imprescriptibles, por razones diferentes". Hinestrosa Forero, Fernando. La prescripción extintiva. Ed. Universidad Externado de Colombia, p. 35, (2000).

${ }_{5}^{5}$ Pérez Vives, Álvaro. Teoría General de las obligaciones, Ed. Universidad Nacional de Colombia, pp. 458 y ss. (1957) y Bonivento JimÉnez, José Armando. Obligaciones, Ed. Legis, p. 479, (2017).

${ }^{6}$ Arias, Antonio Emiro Thomas. Nuevo régimen de prescripción civil. Vniversitas, Vol. 52, Núm. 105. 2003. At. 211.
} 
acción y del derecho propiamente tal, hasta el punto que la obligación se extingue como obligación civil, para quedar simplemente como obligación natural, conforme lo puntualiza inequívocamente el ordinal $2^{\circ}$ del art. 1527 del Código Civil (...).

Así, el propio Código Civil, en la regulación misma de la prescripción, anuncia casos de acciones que prescriben en corto tiempo, tres y dos años en los eventos que para efecto citan los arts. 2542 y 2543 , advirtiendo que se trata de supuestos concebidos en el contexto de la época de expedición de la norma, (...) [y] a lo largo del Código Civil, al igual que en el Código de Comercio, se encuentran múltiples situaciones jurídicas en las que la ley opta por consagrar tiempos especiales para efectos del ejercicio de acciones judiciales encaminadas a hacer valer derechos de orden sustancial, bajo la calificación explícita de prescripción, por fuera de la regla general; en materia civil, a manera de ilustración selectiva en función de la mayor cercanía temática con el derecho de las obligaciones -incluyendo sus fuentes-, pueden citarse los casos de los arts. 1913 -acción de saneamiento por evicción en la compraventa-, 1926 - acción de saneamiento por vicios ocultos o redhibitorios-, y 2358 -acción de indemnización de perjuicios por delito o culpa (...) en materia comercial, con el mismo criterio selectivo pueden mencionarse los casos de los arts. 938 -acción de saneamiento por vicios ocultos o redhibitorios-, 1081 -acciones derivadas del contrato de seguro- (...)".

En síntesis, la prescripción es un modo de extinguir las obligaciones en virtud del simple paso del tiempo, cuya existencia se justifica en la necesidad del ordenamiento jurídico de concretar determinadas situaciones jurídicas con efecto en el campo jurídico derivadas de la inacción del acreedor dentro de un tiempo determinado por la ley cuyo cómputo se inicia una vez la obligación se torna exigible ${ }^{7}$.

\subsection{El art. 1081 del Código de Comercio y el cómputo de la prescripción en materia de seguros}

El art. 1081 del Código de Comercio consagra un régimen especial de prescripción aplicable al contrato de seguros y a las acciones que se derivan de las disposiciones que lo rigen, regulándose en este no sólo los términos necesarios para la configuración del fenómeno prescriptivo, sino también el momento a partir del cual deben compu$\operatorname{tarse}^{8}$, al señalar expresamente que:

“Art. 1081. Prescripción de acciones. La prescripción de las acciones que se derivan del contrato de seguro o de las disposiciones que lo rigen podrá ser ordinaria o extraordinaria. La prescripción ordinaria será de dos años y empezará a correr desde el momento en que el interesado haya tenido o debido tener conocimiento del hecho que da base a la acción. La prescripción extraordinaria será de cinco años, correrá contra toda clase de personas y empezará a contarse desde el momento en que nace el respectivo derecho. Estos términos no pueden ser modificados por las partes".

En relación con la norma transcrita, es necesario mencionar que el sistema de prescripción aplicable al contrato de seguro y las normas que regulan las acciones que de él se derivan se caracteriza por ser plural, especial y omnicomprensivo, en la medida en que no sólo establece dos tipos diferenciados de prescripción, a saber la ordinaria

\footnotetext{
7 Ospina Fernández, Guillermo. Régimen General de las obligaciones. Ed. Temis, (2005), pp. 464-465. .

8 Superintendencia Financiera de Colombia. Concepto No. 1999035395-2 (agosto 20 de 1999).
} 
o subjetiva y la extraordinaria u objetiva, sino que dichos términos de prescripción aplican a la totalidad de las acciones derivadas del contrato de seguro y las normas que consagran su regulación ${ }^{9}$. En efecto, tal y como lo ha sostenido de larga data la Corte Suprema de Justicia ${ }^{10}$ :

“(...) el texto del precepto transcrito se observa que con claridad se refiere, sin distingos de ninguna clase, a 'La prescripción de las acciones que se derivan del contrato de seguros'; lo que significa que abarca o comprende todos los medios legales existentes para que los sujetos que se encuentran formando parte de tal tipo de relación contractual, o con interés en ella y sus efectos, puedan acudir a la jurisdicción, a fin de que se les administre justicia respecto del litigio que se suscite en relación con la misma. En otras palabras: todas las acciones que tengan como soporte el contrato de seguro, sea que busquen la satisfacción del derecho, como acontece con la de ejecución, sea que persigan su esclarecimiento o reconocimiento, como sucede con las de naturaleza cognoscitiva, están sometidas inexorablemente a los plazos extintivos que prevé el art. 1.081 del ordenamiento comercial".

En relación con la naturaleza plural del contrato de seguro, en virtud de la cual se regula el momento a partir de la cual corre el término de prescripción, se tiene que:

“(...) cuando se trata de acciones dirigidas a exigir del asegurador la indemnización pactada por haber operado el amparo, distingue entre el momento en que el interesado, quien deriva un derecho del contrato de seguro, ha tenido o debido tener conocimiento del hecho que da base a la acción, en la prescripción ordinaria y, el momento del nacimiento del derecho, independientemente de cualquier circunstancia y aun cuando no se pueda establecer si el interesado tuvo o no conocimiento de tal hecho, en la extraordinaria. Se destaca entonces, el conocimiento real o presunto del hecho que da base a la acción, como rasgo que diferencia la prescripción ordinaria de la extraordinaria, pues en tanto la primera exige la presencia de este elemento subjetivo, la segunda no"ll.

A partir de lo expuesto se tiene que la prescripción ordinaria o subjetiva, se configura en un término de dos (2) años y opera, al tenor de lo dispuesto en el art. 1081 del Código de Comercio, desde el momento del "conocimiento", real o presunto, que tenga el interesado del hecho que da base a la acción.

"Ello es así, en la medida en que la comentada disposición hizo depender, la primera, del "conocimiento" "que el interesado haya tenido o debido tener del hecho que da base a la acción" y la segunda, del "momento en que nace el respectivo derecho". En tal virtud, la operación de aquella implica el "conocimiento" real o presunto por parte del titular de la respectiva acción, en concreto, de la ocurrencia del hecho que la genera, cuestión que dependerá, por tanto, no del acaecimiento del mismo, desde una perspectiva ontológica $y$, por ende, material, sino del instante en que el interesado se informó de dicho acontecer o debió saber de su realización, vale decir desde que se volvió cognoscible, o por lo menos pudo volverse" ${ }^{12}$ (Destacado fuera del texto original).

\footnotetext{
9 López Blanco, Hernán Fabio. Comentarios al contrato de seguro, Ed. Dupre. (2010), p. 241

10 Corte Suprema de Justicia. Sala de Casación Civil. (M.P. Alberto Ospina Botero; marzo 4 de 1989).

11 Superintendencia Financiera de Colombia. Concepto No. 1999040521-2 (agosto 20 de 1999).

12 Corte Suprema de Justicia. Sala de Casación Civil. Proceso 4690 (M.P. Carlos Ignacio Jaramillo Jaramillo; junio 29 de 2007).
} 
De otra parte, la prescripción extraordinaria u objetiva, se configura en un término de cinco (5) años contados desde el momento que nace el respectivo momento a solicitar la indemnización con independencia de cualquier consideración subjetiva, en la medida en que corre contra toda clase de personas no siendo plausible de suspensión. En efecto, el art. 1081 del Código de Comercio:

“(...) señaló que la prescripción extraordinaria irrumpirá a partir del surgimiento, en el cosmos jurídico, del respectivo derecho, independientemente de cualquier enteramiento que sobre su existencia tenga o no el titular; basta pues su floración, como tal, para que la prescripción extraordinaria empiece a correr. De ahí su caracterizada y anunciada objetividad, que se contrapone, por completo, a la más mínima subjetividad (...)" (Destacado fuera del texto original) ${ }^{13}$.

En línea con lo anterior, resulta necesario afirmar que, si bien la prescripción ordinaria y la prescripción extraordinaria son en efecto independientes, ambas corren de forma simultánea dándose aplicación a la primera de ellas que se configure de forma efectiva, sin que para todos los efectos le sea dado a la aseguradora, tomador, asegurado o beneficiario escoger cual aplicar en un caso concreto, pues la prescripción extraordinaria sólo afectará las acciones derivadas del contrato de seguro y las leyes que lo rigen, cuando con anterioridad no se hubieran dado los presupuestos para la configuración de la prescripción ordinaria contemplada en el art. 1081 en mención ${ }^{14}$, de allí que sea : “(...) el plazo de dos años a que hace referencia la prescripción ordinaria, siempre queda supeditado al plazo máximo de los cinco años, correspondientes a la prescripción extraordinaria" 15 .

De esta forma, tal y como lo ha dispuesto en reiteradas ocasiones la jurisprudencia:

“(...) el anotado término de dos años irrumpe desde cuando el titular conoció o debió conocer la ocurrencia del hecho que habilita su ejercicio, como ya tangencialmente se mencionó. Al respecto, desde un ángulo jurídico-temporal, pertinente es destacar que uno es el momento de ocurrencia del hecho y otro aquél en que el accionante supo o debió saber de su acaecimiento, sin perjuicio, claro está, de que en casos específicos, como suele suceder con inusitada frecuencia en la praxis, puedan darse las dos circunstancias en un mismo tempus. La extraordinaria se inicia a partir de cuando nace el derecho, objetivamente considerado. Por ello, conforme ya se observó, opera frente a toda clase de personas y al margen de cualquier conocimiento (real o efectivo, presunto o presuntivo)"16 (Destacado fuera del texto original).

Es importante resaltar que los plazos contemplados en el art. 1081 del Código de Comercio son para todos los efectos inmodificables, en la medida en que como lo sostiene el Dr. J. Efrén Ossa

\footnotetext{
${ }_{13}$ Corte Suprema de Justicia. Sala de Casación Civil. Proceso 4690 (M.P. Carlos Ignacio Jaramillo Jaramillo; junio 29 de 2007).

14 Corte Suprema de Justicia. Sala de Casación Civil. Proceso 4690 (M.P. Carlos Ignacio Jaramillo Jaramillo; junio 29 de 2007)

15 Collazos Rivera, Juan Camilo \& Fajardo Gutiérrez, Lucas. Prescripción en el contrato de seguro ¿tradición o modernismo? Revista Ibero latinoamericana de Seguros, Vol. 32, Núm. 19. 2010. At.73, p. 87

${ }_{16}$ Corte Suprema de Justicia. Sala de Casación Civil. Proceso 4690 (M.P. Carlos Ignacio Jaramillo Jaramillo; junio 29 de 2007).
} 
"El Art. 1081 del Código de Comercio, que regula la prescripción de las acciones a que da origen el contrato de seguro, es norma imperativa por su naturaleza y por su texto, en cuya rigurosa observancia está interesado el orden público"17;

nótese que la prohibición de modificación no sólo se aplica a los plazos, sino a cualquier alteración que en el marco de la negociación contractual se realice a

“(...) sus puntos de partida, que no [podrán] ser susceptible de anticipación o aplazamiento, las reglas de suspensión con el espíritu que las anima, que no podría ser burlado por el asegurador, y aún la naturaleza de las acciones a que se aplica"18.

Ahora bien, es importante resaltar que existe cuando menos una excepción frente al momento a partir del cual debe computarse el término de prescripción, en atención a la conducta de las partes en relación con la celebración o ejecución del contrato. En efecto, es posible diferir el momento a partir del cual se computa la prescripción al establecer, por ejemplo, el forzoso agotamiento previo de una determinada actuación para solicitar la indemnización derivada de un determinado hecho dañoso amparado bajo el contrato de seguro.

De allí que, tal y como lo puso de presente el Tribunal Arbitral de Alstom Brasil contra la Compañía Suramericana Seguros S.A. (hoy Seguros Generales Suramericana S.A.) mediante el laudo del 14 de septiembre de 2006 con ponencia de Carlos Esteban Jaramillo, Antonio Pabón Santander y Alejandro Venegas Franco al resolver una controversia entorno a un contrato de seguro en cuya literalidad se había dispuesto que la "(...) cuantificación de la perdida sería efectuada por una firma ajustadora, incluso designada contractualmente, la reclamación no se podía entender perfeccionada hasta tanto se rindiera el informe final de ajuste", no es posible que en un caso como el enunciado se compute la prescripción desde el momento mismo en que ocurre el hecho que da base a la acción, sin que ello implique un desconocimiento de lo dispuesto en el art. 1081 del Código de comercio, pues hasta que no se cumpliera con el requisito contractualmente establecido no podía entenderse perfeccionada la reclamación, razón por la cual afirma el Tribunal que:

“(...) la prescripción para que sea eficaz en los precisos términos de la legislación aplicable debe provenir de una conducta del acreedor, esto es, de su inactividad, pero no de la de un tercero, como lo sería si la inmovilidad fuese atribuible a la sociedad ajustadora Crawford, designada desde la celebración del contrato como llamada a definir el siniestro con su conclusión técnica. El beneficiario reclamante de la indemnización, se reitera, podía disponer lo pertinente para hacer valer su derecho tan sólo cuando se presentara el informe rendido por la firma ajustadora: con anterioridad, siguiendo los lineamientos de la estipulación pertinente, no le era posible accionar frente a la organización de justicia anteladamente a dicha ocasión. pues desconocía si el siniestro como tal estaba cubierto, si la entidad aseguradora efectuaba o no objeción o si ésta era extemporánea o no.

(...) por la complejidad del siniestro y por el modo como las partes del contrato convinieron la forma de adquirir ese conocimiento que exige la ley en interés de ambas, no ha habido configuración de la prescripción que hubiese tenido como sopor-

${ }_{17}$ Ossa Gómez, José Efrén. Teoría General del Seguro: El contrato. Ed. Temis (1991), p. 533.

${ }^{18}$ Ossa Gómez, José Efrén. Teoría General del Seguro: El contrato. Ed. Temis (1991), p. 533. 
te el abandono en el ejercicio de derecho que pueda atribuirse al tomador. Pero visto desde la perspectiva de la interrupción de la prescripción, debe indicarse que conocido en su integridad el siniestro con la presentación del informe de ajuste, el cual, se reitera, en los términos de la condición contractual así se encuentra previsto, $\underline{\text { se tiene que rendido ese informe el } 16 \text { de abril de } 2003 \text { y presentada la demanda ante }}$ la jurisdicción común el 8 de abril de 2005, la prescripción se interrumpió dentro de los límites temporales fijados por la legislación y no impide el ejercicio de los derechos por parte del tomador, reclamante de la indemnización" (Destacado fuera del texto original).

En sintesis, la prescripción aplicable al contrato de seguro y las acciones derivadas de las normas que lo regulan, al tenor de lo dispuesto en el art. 1081 del Código de Comercio, hace alusión a una prescripción extintiva que, de forma particular para el ordenamiento jurídico en que se integra, posee un carácter plural y omnicomprensivo. Ello es así en la medida en que la misma disposición normativa contempla dos (2) plazos de prescripción, uno ordinario o subjetivo y otro extraordinario u objetivo, los cuales corren para todos los efectos de forma paralela aplicándose el primero de aquellos que se configure, sin que sea potestativo de los interesados determinar cual de ellos emplear en una situación determinada.

\subsection{El art. 1131 del Código de Comercio y el cómputo de la prescripción en materia de seguros}

Tal y como se señaló someramente con anterioridad, la prescripción en materia del Seguro de Responsabilidad Civil se rige conforme a lo dispuesto en el art. 1131 del Código de Comercio, por lo que si bien se trata de una norma que debe interpretarse en concordancia con los términos dispuestos en el art. 1081 de la misma disposición normativa, los supuestos fácticos que la constituyen merecen una especial revisión que debe partir, en todo caso, de analizar la literalidad de lo consignado en ella por el legislador, en los siguientes términos:

“Art. 1131. Ocurrencia del siniestro. En el seguro de responsabilidad se entenderá ocurrido el siniestro en el momento en que acaezca el hecho externo imputable al asegurado, fecha a partir de la cual correrá la prescripción respecto de la victima. Frente al asegurado ello ocurrirá desde cuando la víctima le formula la petición judicial o extrajudicial".

Ahora bien, de la disposición normativa transcrita es posible deducir las siguientes premisas:

1. La prescripción de la acción directa de la víctima inicia su cómputo desde el momento en que acaezca el hecho externo imputable al asegurado.

2. La prescripción respecto del asegurado inicia su cómputo desde cuando la victima le formula una petición judicial o extrajudicial de reparación.

La configuración de dichas premisas resulta clara si se toma en consideración lo afirmado por el Dr. Nicolás URIBE LOZADA en relación con el contenido de la disposición normativa consagrada en el art. 1131 del Código de Comercio, al considerar que entendiéndose el hecho dañoso como el siniestro bajo esta tipología de seguros: 
“(...) es menester, distinguir dos momentos marcadamente diferentes, el primero, aquel relativo a la ocurrencia del siniestro que estará señalado por el acaecimiento del hecho externo imputable al asegurado, que por cierto será el elemento o requisito constitutivo o de existencia de cobertura en el seguro de responsabilidad contratado. Y un segundo momento, que corresponderá a la reclamación que formule la víctima al asegurado que, para los efectos del contrato de seguro de responsabilidad bajo la modalidad por ocurrencia, marcará únicamente requisito de mera exigibilidad y, por ende, supeditará el inicio del cómputo del término de prescripción de las acciones derivadas del contrato de seguro otorgadas a favor del asegurado" 19 .

Retomando el análisis planteado, en relación con la primera de las premisas que se deducen del art. 1131, es necesario manifestar que, tal y como de larga data lo ha sostenido la Corte Suprema de Justicia ${ }^{20}$ a la víctima sólo le es aplicable la prescripción extraordinaria de cinco (5) años en la medida en que:

“(..) 3.2. (...) se impone entender que [el art. 1131] no consagró un sistema de prescripción extraño o divergente al global desarrollado en el precitado precepto [alude al art. 1081] y que, por contera, sus disposiciones no constituyen un hito legislativo aislado o, si se prefiere, autónomo o propio, de suerte que, para su recta interpretación, debe armonizársele con ese régimen general que, en principio, se ocupó de regular el tema de la prescripción extintiva en el negocio aseguraticio y que, por tanto, excluye toda posibilidad de recurrir a normas diferentes $y$, mucho menos, a las generales civiles, (...) como quiera que, muy otra, es la preceptiva inmersa en la codificación civil, a lo que se suma la especialidad normativa del régimen mercantil, como tal llamada a primar y, por tanto, a imperar (...) Y es dentro de ese contexto, que adquiere singular importancia la referencia expresa que el comentado art. 1131 hace en punto al momento en que 'acaezca el hecho externo imputable al asegurado', para establecer la ocurrencia del siniestro y, por esta vía, para determinar que es a partir de ese instante, a manera de venero, que 'correrá la prescripción respecto de la víctima', habida cuenta que cotejada dicha mención con el régimen general del art. 1081, resulta más propio entender que ella alude a la prescripción extraordinaria en él consagrada, a la vez que desarrollada, ya que habiendo fijado como punto de partida para la configuración de la prescripción de la acción directa de la víctima, la ocurrencia misma del hecho generador de la responsabilidad del asegurado -siniestro-, es claro que optó por un criterio netamente objetivo, predicable solo, dentro del sistema dual de la norma en comentario, como ya se señaló, a la indicada prescripción extraordinaria, ya que la ordinaria, como también en precedencia se indicó, es de estirpe subjetiva, en la medida en que se hace depender del 'conocimiento' real o presunto del suceso generador de la acción, elemento este al que no aludió la primera de las normas aquí mencionadas, ora directa, ora indirectamente, aspecto que, por su relevancia, debe ser tomado muy en cuenta.

Por consiguiente, aun cuando los cánones 1081 y 1131 del Código de Comercio deben interpretarse conjunta y articuladamente, según se evidenció, tampoco es menos cierto que el segundo de ellos, al fijar como único percutor de la prescripción de la acción directa de la víctima en un seguro de responsabilidad, la ocurrencia misma

\footnotetext{
19 Uribe Lozada, Nicolás. Análisis técnico-jurídico de la modalidad de cobertura por reclamación o "Claims made" en los seguros de responsabilidad civil a la luz del ordenamiento jurídico colombiano, Revista Ibero Latinoamericana de Seguros, Vol. 44, Núm. 25, 2016. At. 13, p. 21.

${ }^{20}$ Corte Suprema de Justicia, Sala de Casación Civil. Proceso No. 7173 (M.P. Cesar Julio Valencia Copete; febrero 10 de 2005) y Corte Suprema de Justicia. Sala de Casación Civil. Proceso 2000-00428 (M.P. Jaime Alberto Arrubla Paucar; septiembre 20 de 2010).
} 
del siniestro, pudiendo haber tomado otra senda o camino, optó por la prescripción extraordinaria que, por contar con un término más amplio -cinco años-, parece estar más en consonancia con el principio bienhechor fundante de dicha acción que (...) no es otro que la efectiva y real protección tutelar del damnificado a raíz del advenimiento del hecho perjudicial perpetrado por el asegurado, frente al asegurador, propósito legislativo que, de entenderse que la prescripción aplicable fuera la ordinaria de dos años, por la brevedad del término, en compañía de otras vicisitudes, podría verse más comprometido, en contravía de su genuina y plausible teología" -La Sala hace notar(Sent. Cas. 29 de junio de 2007, expediente 1998-04690 01).

De la evocación efectuada surgen prontamente y sin dubitación alguna, postulados de las siguientes características: i) la prescripción prevista en el art. 1131 del C. de Co., en tratándose de un seguro de responsabilidad civil, cuando la víctima acciona es, sin duda, de cinco años, o sea, la extraordinaria; ii) que, por lo mismo, la consagración de dicho aspecto temporal deviene, claramente, demarcada por matices objetivos y no subjetivos; iii) esto último significa que el término cuenta a partir del acaecimiento del siniestro o el hecho imputable al asegurado, independientemente que lo haya conocido o no el afectado; además, corre frente a toda clase de personas, inclusive los incapaces.

Aflora así mismo y de manera incontestable, que tratamiento normativo de semejante talante impone la concurrencia de un elemento imprescindible, definitivo, en verdad, para fijar el sentido de la decisión reclamada, como es que la víctima haya sido quien acometió la acción judicial en contra de la aseguradora, o sea, comporte el ejercicio de un accionar directo (arts. 84 y 87 de la Ley $N^{\circ} 45$ de 1990); en otros términos, los efectos favorables que el actor pretende derivar de la norma invocada podrán producirse siempre y cuando la litis involucre como demandante al agredido y como demandada a la aseguradora y, por supuesto, concierna con el seguro de responsabilidad civil. No aconteciendo así, lisa y llanamente, la disputa devendría gobernada por disposiciones diferentes, pues es evidente que la que en esos términos prescribe es la acción directa de la víctima contra la empresa aseguradora. O, para decirlo más explícitamente, tal hipótesis concurre en la medida en que la reclamación judicial involucre a la víctima como accionante y, en la parte demandada, a la sociedad emisora del seguro (...)"²1.

En relación con la segunda premisa susceptible de ser deducida del art. 1131 del Código de Comercio, han establecido tanto la doctrina como la jurisprudencia que la prescripción que corre en contra del asegurado en materia del Seguro de Responsabilidad Civil es para todos los casos la ordinaria aplicable al contrato de seguro computada desde el momento en que le ha sido formulada judicial o extrajudicialmente la solicitud de indemnización, sin que pueda, en supuesto alguno iniciarse el cómputo con anterioridad a dicha reclamación ${ }^{22}$. Ello resulta apenas lógico si se toma en consideración que tal y como lo sostenía el Dr. Efrén OssA al tenor de lo dispuesto en el art. 1530 del Código Civil la reclamación judicial o extrajudicial de una indemnización por parte del tercero es "(...) un acontecimiento futuro, que puede suceder o no" ${ }^{23} \mathrm{y}$ por lo tanto constituye una condición de la cual pende la obligación indemnizatoria del asegurador en relación con el asegurado, contra quien no puede correr la pres-

\footnotetext{
${ }^{21}$ Corte Suprema de Justicia. Sala de Casación Civil. Proceso 2004-00142 (M.P. Pedro Octavio Munar Cadena; mayo 25 de 2011).

22 Corte Suprema de Justicia. Sala de Casación Civil. Proceso STC-139482019 (M.P. Octavio Augusto Tejeiro Duque; octubre 11 de 2019).

23 Ossa Gómez, José Efrén. Teoría General del Seguro: El contrato. Ed. Temis (1984), p. 467.
} 
cripción con anterioridad a la comprobación de dicha condición en la medida en que conforme a lo dispuesto en el art. 2530 del Código Civil se encuentra en imposibilidad de hacer valer su derecho por no ser exigible.

De allí que tal y como lo ha sostenido la Dra. Hilda Zornosa el plazo de prescripción para el asegurado deberá computarse tomando en consideración que

"como el plazo general de prescripción de la acción extracontractual de responsabilidad de la víctima contra el asegurado es de diez años, si no hubo reclamo extrajudicial del damnificado el término de prescripción de la acción del asegurado en contra del asegurador puede llegar a extenderse a doce años"24.

Es importante precisar, sin embargo, que el plazo potencial para la configuración efectiva de la prescripción superaría los doce (12) años, bajo el imperio de la Ley $\mathrm{N}^{\circ} 1564$ de 2012, si se añade a la consideración realizada por la Dra. ZORNOSA ${ }^{25}$ las siguientes premisas:

1. Conforme a lo dispuesto en el art. 94 de dicho estatuto normativo la prescripción se entiende interrumpida con la presentación del escrito de demanda siempre y cuando se notifique al demandado del auto admisorio dentro del término de un (1) año contado desde la notificación de dicha providencia al demandante.

2. Tal y como lo ha sostenido el Dr. Juan Manuel DíAz-Granados el llamamiento en garantía presentado en contra de una aseguradora interrumpe la prescripción en la medida en que “(...) según lo señala Jairo Parra Quijano, "implica innegablemente el ejercicio de la acción" ". Por lo que el auto admisorio del llamamiento en garantía, en ausencia de norma expresa, deberá notificarse igualmente de acuerdo a lo establecido en el articulo enunciado, esto es dentro del año siguiente a su notificación al llamante.

Conforme a lo anterior, no sólo debe tomarse en consideración el término de prescripción de la acción extracontractual de la víctima en contra del asegurado equivalente a diez (10) años y la subsiguiente prescripción del derecho en cabeza de este, para solicitar la correlativa indemnización a la aseguradora en un lapso de dos (2) años, sino también el plazo con el que cuenta el demandante para notificar al demandando del auto admisorio de la demanda, así como el potencial tiempo para la notificación del llamamiento en garantía o la demanda por parte del asegurado a la aseguradora.

Pese a la disquisición realizada hasta ahora en relación con el momento en que empieza a principiar el cómputo de la prescripción en materia del seguro de responsabilidad civil, es necesario mencionar que con ocasión del laudo arbitral proferido el día 05 de marzo de 2009 por Carlos Esteban Jaramillo, Carlos Ignacio Jaramillo y José Fernando Torres al interior del Tribunal Arbitral de Beneficencia del Valle del Cauca contra La Previsora S.A. Compañía de Seguros, se estableció a partir de la doctrina de los

\footnotetext{
24 Zornoza Prieto, Hilda Esperanza. El seguro de Responsabilidad Civil su evolución normativa y jurisprudencial en Colombia. Revista Ibero Latinoamericana de Seguros, Vol. 35, Núm. 20. 2011. At. 85. , p. 120.

25 Zornoza Prieto, Hilda Esperanza. El seguro de Responsabilidad Civil su evolución normativa y jurisprudencial en Colombia. Revista Ibero Latinoamericana de Seguros, Vol. 35, Núm. 20. 2011. At. 85.

26 Díaz Granados, Juan Manuel. Las acciones relacionadas con el seguro de responsabilidad. Revista Ibero Latinoamericana de Seguros, Vol. 28, Núm. 17. 2008. At. 67., pp. 100-101.
} 
actos propios que aún cuando hubiese transcurrido el término legal para la configuración de la prescripción, resulta inadmisible invocar la misma como excepción cuando se fundamenta en:

\section{“(...) hechos que contraríen sus propias afirmaciones 0 asuma una actitud que lo coloque en oposición con su conducta anterior, lo que entraña ...una inadmisibi- lidad o veda de ir contra los propios actos, y constituye técnicamente un límite del ejercicio de un derecho subjetivo o de una facultad reconocida al sujeto que luego pretende variar de comportamiento".}

En la medida en que ello constituiría un ejercicio irregular o abusivo de la excepción de prescripción dado que:

“(...) el demandado, según el sentido objetivo de su conducta y de acuerdo con la buena fe, ha suscitado en el demandante la confianza inequívoca o paladina de que la prescripción no sería invocada, de tal modo que con base en esa confianza, el demandante ha dejado transcurrir los plazos de prescripción sin ejercitar su pretensión (...)".

Lo anterior, resulta apenas lógico si se toma en consideración que tal y como lo sostiene el Dr. Carlos Ignacio Jaramillo, en línea con el principio Venire Contra Factum Propium Non Valet a nadie le:

“(...) está permitido volver -o ir- contra sus propios actos -o sea contrariarlos o contradecirlos- (venire contra factum propium, o venire contra factum propium nulla conceditur), cuando ellos generaron, objetivamente, una confianza, creencia o certidumbre determinadas; un entendimiento racional diverso que, ex post, se vio trocado, y también truncado sorpresivamente, siendo entonces menester proceder a tutelar los intereses materia de amenaza o vulneración, a manera de plausible correctivo, en clara sintonía con el acrisolado postulado de la buena fe que, ab initio, rechaza este tipo de comportamientos incoherentes y contradictorios que originan inseguridad e incertidumbre jurídicas, y también con la preservación de la confianza generada o inculca, clave de bóveda de esta institución"27.

En síntesis, para esta tipología de seguro, se tiene que la prescripción se encuentra regida por las disposiciones especiales contenidas en el art. 1131 del Código de Comercio, a partir del cual ha entendido tanto la doctrina como la jurisprudencia que la prescripción de la acción en cabeza de la victima se computa en el termino dispuesto para la prescripción extraordinaria desde el momento en que acaezca el hecho externo imputable al asegurado, mientras que, para este último, el término de la prescripción será el ordinario de dos (2) años contado a partir del momento en que la víctima le formule una petición judicial o extrajudicial de reparación.

\footnotetext{
27 En relación con el particular, ha sostenido la doctrina que constituyen presupuestos para la configuración de los actos propios, los siguientes “(i) La realización de una conducta anterior jurídicamente relevante, vinculante y eficaz de un sujeto; (ii) El ejercicio posterior por parte del mismo sujeto de una facultad o derecho subjetivo que resulta contradictorio con su conducta anterior, y (iii) La identidad de los sujetos que actúan y se vinculan en ambas conductas". Collazos Rivera, Juan Camilo \& Fajardo Gutiérrez, Lucas. Prescripción en el contrato de seguro ¿tradición o modernismo? Revista Ibero latinoamericana de Seguros, Vol. 32, Núm. 19. 2010. At. 73, p. 98 y Jaramillo Jaramillo, Carlos Ignacio. La doctrina de los actos propios y su proyección en la esfera del derecho de los contratos. Estudios de Derecho Privado Tomo 1. Ed. Universidad del Rosario (2009), p. 280.
} 


\subsection{Algunas consideraciones en torno a la suspensión e interrupción del cómputo de la prescripción}

\subsubsection{Consideraciones respecto a la suspensión de la prescripción}

Toda vez que el Código de Comercio no regula de forma siquiera sumaria los fenómenos jurídicos de la suspensión y la interrupción del cómputo de la prescripción, resulta necesario en atención a la expresa remisión realizada por el art. 822 de dicho cuerpo normativo, hacer uso de las pautas dispuestas en el Código Civil para delimitar los supuestos bajo los cuales procedería la aplicación de dichas figuras ${ }^{28}$. En lo que atañe a la suspensión de la prescripción, establece el Código Civil, lo siguiente:

“Art. 2530. Suspensión de la prescripción ordinaria. La prescripción ordinaria puede suspenderse sin extinguirse; en ese caso, cesando la causa de la suspensión, se le cuenta al poseedor el tiempo anterior a ella, si alguno hubo.

La prescripción se suspende a favor de los incapaces y, en general, de quienes se encuentran bajo tutela o curaduría.

Se suspende la prescripción entre el heredero beneficiario y la herencia.

Igualmente se suspende entre quienes administran patrimonios ajenos como tutores, curadores, albaceas o representantes de personas jurídicas, y los titulares de aquellos.

No se contará el tiempo de prescripción en contra de quien se encuentre en imposibilidad absoluta de hacer valer su derecho, mientras dicha imposibilidad subsista".

Al tenor de lo dispuesto en la norma transcrita resulta posible afirmar que la prescripción ordinaria derivada de las normas que regulan el contrato de seguro es susceptible de suspenderse en favor de los incapaces, al mismo tiempo que no es pasible de ser computada en relación con "(...) las personas que no tuvieron ni pudieron tener conocimiento del hecho que da base a la acción"29, este último supuesto bajo el entendido que al existir ignorancia excusable por parte del asegurado o beneficiario de la ocurrencia del hecho que da base a la acción según lo prevé el art. 1081 del Código de Comercio, se configuraría un supuesto de imposibilidad de hacer valer el derecho a la indemnización.

En línea con lo expuesto, resulta claro que la prescripción extraordinaria contemplada en el art. 1081 del Código de Comercio no es susceptible de ser suspendida, no sólo por cuanto el art. 2530 del Código Civil hace referencia únicamente a la suspensión de la prescripción ordinaria, sino por cuanto de la redacción misma del artículo que regula su cómputo en materia de seguros es claro que corre contra toda clase de personas, incluyendo por lo tanto a los incapaces, y aún contra quienes no tuvieron, ni pudieron tener conocimiento del hecho que sustenta la acción ${ }^{30}$.

${ }_{28}$ Superintendencia Financiera de Colombia. Concepto No. 1999040521-2 (agosto 20 de 1999).

29 Superintendencia Financiera de Colombia. Concepto No. 2006051752-001 (diciembre 22 de 2006).

${ }^{30}$ Superintendencia Financiera de Colombia. Concepto No. 2006051752-001 (diciembre 22 de 2006). 
“(...) La expresión 'contra toda clase de personas' debe entenderse en el sentido de que el legislador dispuso que la prescripción extraordinaria corre aun contra los incapaces (art. 2530 numeral $1^{\circ}$ y 2541 del C.C.), así como contra todos aquellos que no hayan tenido ni podido tener conocimiento del siniestro (...) el legislador utilizó dos locuciones distintas para expresar una misma idea, como ocurre con las que aparecen en los incisos $2^{\circ}$ y $3^{\circ}$ del art. 1081, acaso para no incurrir en repeticiones o para destacar lo que se expuso respecto de los incapaces en el párrafo anterior (...)" ${ }^{31}$.

En íntima concordancia con lo anterior, resulta menester indicar que la prescripción de las acciones derivadas del contrato de seguro no empieza a correr en tanto exista desconocimiento del hecho que da base a la acción, más no por el desconocimiento del contrato de seguro en cuestión, en la medida en que tal y como lo ha manifestado la Superintendencia Financiera de Colombia en relación con la prescripción ordinaria contemplada en el art. 1081 del Código de Comercio:

"Como quiera que el término de la prescripción ordinaria comienza a contarse a partir de la fecha en que el beneficiario haya tenido o debió tener conocimiento de la ocurrencia del siniestro (...) y, si desde esa fecha han transcurrido dos años, 'las acciones que se derivan del contrato de seguro o de las disposiciones que los rigen 'están prescritas.

En este orden, es el conocimiento mismo que se tenga de la ocurrencia del siniestro el que marca la pauta para que empiece a correr en contra del beneficiario el término de la prescripción ordinaria y no, el desconocimiento que éste tenga de la existencia del contrato de seguro" 32 .

En punto de la exposición hasta ahora realizada, es necesario enunciar que un supuesto adicional de suspensión fue consagrado por el legislador en relación con la solicitud del trámite de conciliación extrajudicial dispuesto en el art. 21 de la Ley $\mathrm{N}^{\circ} 640$ de 2001 con ocasión del cual es posible suspender la prescripción en virtud de la radicación de la solicitud de conciliación extrajudicial hasta por tres (3) meses, conforme a lo expresamente consagrado en el mismo, así:

"Art. 21. Suspensión de la prescripción o de la caducidad. La presentación de la solicitud de conciliación extrajudicial en derecho ante el conciliador suspende el término e prescripción o de caducidad, según el caso, hasta que se logre el acuerdo conciliatorio o hasta que el acta de conciliación se haya registrado en los casos en que este trámite sea exigido por la ley o hasta que se expidan las constancias a que se refiere el art. $2^{\circ}$ de la presente ley o hasta que se venza el término de tres (3) meses a que se refiere el artículo anterior, lo que ocurra primero. Esta suspensión operará por una sola vez y será improrrogable" (Destacado fuera del texto original).

Es importante mencionar que, contrario a lo referido en relación con el art. 2530 del Código Civil, es necesario considerar que la solicitud de conciliación extrajudicial reglada en el art. 21 de la Ley $N^{\circ} 640$ de 2001 tiene la facultad de suspender hasta por tres (3) meses aún la prescripción extraordinaria en materia de derecho de seguros, en la medida en que no sólo la norma no hizo distinción alguna entre la prescripción ordinaria y la extraordinaria, sino que al constituir un requisito de procedibilidad el agotamiento de la conciliación extrajudicial al tenor de lo dispuesto en el art. 621 del

\footnotetext{
31 Corte Suprema de Justicia. Sala de Casación Civil. (M.P. José María Esguerra Samper; julio 4 de 1977).

32 Superintendencia Financiera de Colombia. Concepto No. 1999035395-2 (agosto 20 de 1999).
} 
Código General del Proceso mediante el cual se modificó el art. 38 de la Ley $N^{\circ} 640$ de 2001, resulta apenas lógico que dicho tiempo no pueda ser tomado en consideración como el resultado de la inactividad del acreedor que da lugar o justificación al instituto de la prescripción.

Finalmente, es necesario manifestar que existe un supuesto de suspensión adicional de la prescripción en materia del contrato de seguro, aplicable prima facie al "Seguro de Lucro Cesante", en la medida en que tal y como lo estableció la Corte Suprema de Justicia $^{33}$ a partir del concepto del equitable tolling y el precedente del common law Peloso v. Hartford Fire Insurance Co. la naturaleza misma de esta tipología de negocio aseguraticio conlleva a que el inicio del cómputo de la prescripción se difiera en el tiempo al momento de la concreción de la magnitud de la pérdida en la medida en que es sólo a partir de este punto que adquiere contenido obligacional dado que bajo dicha tipología de seguro el supuesto desencadenante de cobertura no es propiamente el hecho condicional, sino la concreción de una perdida derivada de un periodo de disminución de ingresos cuya magnitud sólo puede establecerse una vez terminado el mismo ${ }^{34}$.

\subsubsection{Algunas anotaciones respecto a la interrupción de la prescripción en materia del contrato de seguro}

De otra parte, en lo que refiere a la interrupción de la prescripción se tiene que conforme a lo dispuesto en el art. 2359 del Código Civil:

"Art. 2359. Interrupción natural y civil de la prescripción extintiva. La prescripción que extingue las acciones ajenas puede interrumpirse, ya natural, ya civilmente. Se interrumpe naturalmente por el hecho de reconocer el deudor de la obligación, ya expresa, ya tácitamente. Se interrumpe civilmente por la demanda judicial; salvo los casos enumerados en el art. 2524".

En relación con la interrupción natural de la prescripción, ha sostenido la doctrina que la misma se justifica en la medida en que se trata de un evento que:

“(...) depende de la voluntad del deudor, que es el sujeto menos interesado en que la interrupción se produzca, y por el otro, que el legislador también aquí opta por privilegiar la amplitud de las manifestaciones de voluntad admisibles para producir efectos jurídicos, habilitando la posibilidad de reconocimiento expreso de la obligación, o el escenario de que ello sea en forma tácita, vale decir, deduciéndolo de actos que así lo indiquen con suficiente nitidez" ${ }^{\prime 35}$.

De allí que resulte lógico afirmar que la aceptación de cobertura, de la existencia de un siniestro indemnizable o el mero ofrecimiento de pago parcial por parte de la Aseguradora interrumpen de forma natural la prescripción de las acciones derivadas

\footnotetext{
${ }^{33}$ Corte Suprema de Justicia. Sala de Casación Civil. Proceso SC7814-2016 (M.P. Luis Armando Tolosa Villabona; junio 15 de 2016).

34 TABAREs Cortés, Felipe. El evento desencadenante de la garantía de lucro cesante y el término de la prescripción ordinaria. Revista Ibero Latinoamericana de Seguros, Vol. 45, Núm. 25. 2016. At. 151., p. 171.

35 Bonivento Jiménez, José Armando. Obligaciones. Ed. Legis. (2017), p. 483.
} 
del contrato de seguro. En efecto, tal y como fue sostenido por el Tribunal Arbitral de Favestrella S.A Contra La Previsora y Otros (2010), resulta claro que:

\begin{abstract}
"Ante una oferta específica de pago al beneficiario del seguro, se desprende de manera inequívoca, para ese momento, un claro reconocimiento de la obligación indemnizatoria, que a la luz de lo preceptuado en el art. 2539 del Código civil implica un evento de interrupción natural de la prescripción extintiva, pues, como lo enseña la doctrina autorizada, "el reconocimiento parcial de una deuda por parte del obligado implica interrupción de la prescripción de toda ella".
\end{abstract}

En lo relativo a la interrupción civil de la prescripción de las acciones derivadas del contrato de seguro y/o de las normas que la regulan, resulta claro que la misma se presenta conforme al art. 2359 del Código Civil en virtud de la presentación de la demanda en la medida en que dicho proceder rompe con la "(...) inactividad censurada al acreedor, sin que pase desapercibido que esta modalidad de interrupción depende del propio acreedor, sujeto interesado en que ella se produzca" ${ }^{\prime 36}$.

En relación con la interrupción civil de la prescripción ha sostenido de forma genérica la doctrina que la misma se producirá siempre que:

“(...) el acreedor demandante atienda la carga de notificar personalmente al deudor demandado del auto admisorio de la misma o del mandamiento ejecutivo, dentro del año siguiente a la fecha en que la respectiva providencia es notificada al demandante; si tal notificación al demandado ocurre por fuera del término del año, la interrupción de la prescripción se producirá no en la fecha de presentación de la demanda, sino en la fecha de la correspondiente notificación. El inciso primero del art. 94 del Código General del Proceso es explicitó sobre el particular: La presentación de la demanda interrumpe el término para la prescripción (...) siempre que el auto admisorio de aquella o el mandamiento ejecutivo se notifique al demandado dentro del término de un (1) año contado a partir del día siguiente a la notificación de tales providencias al demandante. Pasado este término, los mencionados efectos solo se producirán con la notificación al demandado.

Es claro, pues, que está en manos del acreedor no correr riesgos en materia de prescripción de su derecho de crédito, mediante la interrupción civil oportuna, aun previendo escenarios de alta dificultad en la atención de la carga procesal de notificación a que se ha hecho referencia" ${ }^{37}$.

En la misma línea de injerencia normativa es claro que también se presenta la interrupción civil de la prescripción de las acciones derivadas del contrato de seguro cuando ocurre el supuesto planteado en el último inciso del art. 94 del Código General del Proceso que establece: "El término de prescripción también se interrumpe por el requerimiento escrito realizado al deudor directamente por el acreedor. Este requerimiento solo podrá hacerse por una vez", y, por tanto:

"Sobra decir, ante la profunda repercusión que esta actuación conlleva, que el acreedor interesado en acudir a ella deberá tomar los recaudos sustanciales y probatorios adecuados a efectos de demostrar, cuando sea avocado a ello, que su actuación ante el

\footnotetext{
36 Bonivento Jiménez, José Armando. Obligaciones. Ed. Legis. (2017), p. 484.

37 Bonivento Jiménez, José Armando. Obligaciones. Ed. Legis. (2017), pp. 484-485.
} 
deudor tiene entidad para constituir ciertamente un requerimiento -lo que, siguiendo el significado de la expresión según su origen del latín, comporta reclamo o exigencia-, y que el mismo efectivamente se realizó, ojalá obteniendo constancia del recibido por el propio deudor, o, por lo menos, acreditando la remisión de la comunicación por medio idóneo y a destino adecuado" 38

A partir de lo anterior, y con fundamento en el art. 94 del precitado Código General del Proceso, es necesario concluir que constituye requisito para que el requerimiento extrajudicial interrumpa civilmente la prescripción que el mismo se haga por intermedio de una comunicación escrita a través de la cual el acreedor le exija a su deudor el cumplimiento de la obligación, al mismo tiempo que le indique expresamente que se considera interrumpida la prescripción de aquella en la medida en que el efecto perseguido con el requerimiento sólo se da una única vez a voluntad del acreedor. De igual forma, resulta claro a partir de la norma transcrita que el requerimiento debe hacerse directamente por el acreedor y que, en todo caso, el deudor debe tener conocimiento de la comunicación en la medida en que la simple remisión sin certeza de su comunicación al destinatario no da lugar a la interrupción del cómputo de la prescripción.

Así las cosas, no podrá entenderse como un requerimiento escrito la mera comunicación encaminada a acreditar la ocurrencia y cuantía del siniestro conforme al art. 1077 del Código de Comercio, tal y como equivocadamente lo sostuvo en un obiter dictum recientemente el Consejo de Estado ${ }^{39}$, en la medida en que tal siguiendo lo sentado por el Tribunal de Bogotát ${ }^{40}$.

"En el caso de la reclamación (...) la sala considera que, por su naturaleza y características, no constituye requerimiento con fines interruptores del plazo prescrip$\underline{\text { tivo }}$, por las siguientes razones:

a. La primera, porque si bien es cierto que la obligación del asegurador despunta o tiene su origen en la ocurrencia del siniestro, esto es, en la realización del riesgo asegurado (C.Co., art. 1054) (...) no lo es menos que el pago de la respectiva indemnización está supeditado a que el asegurado o beneficiario formule una reclamación mediante la cual demuestre que el siniestro tuvo lugar, lo mismo que la cuantía de la pérdida, según el caso, de conformidad con lo previsto en los art. 1077 y 1080 del estatuto mercantil.

Por consiguiente, si en el caso especial del contrato de seguro, la reclamación es una arquetípica carga -de orden sustancial- en cabeza del asegurado o beneficiario, que no sólo es presupuesto de la acción ejecutiva (C.Co., art. 1053), sino también de la mora del asegurador, como lo puntualizó la Corte Suprema de Justicia en sentencia de 30 de septiembre de 2014 (Exp. 7142), no puede ella constituir, al mismo tiempo, ejercicio del derecho del acreedor a interrumpir la prescripción en forma civil. Al fin y al cabo, el propósito fundamental de ese escrito es demostrar, probar o acreditar, de lo que depende, se insiste, el pago de la indemnización.

Es cierto que la obligación del asegurador germinó con la materialización del riesgo;

\footnotetext{
38 Bonivento Jiménez, José Armando. Obligaciones. Ed. Legis. (2017), p. 486.

39 Consejo de Estado. Sala de la Contencioso Administrativo. Sección Tercera. Proceso 63861 (C.P. Marta Nubia Velásquez Rico; marzo 5 de 2020).

40 Tribunal Superior de Bogotá D.C. Proceso 11001-31-03-019-2016-00687-01. (M.P. Marco Antonio Álvarez Gómez: septiembre 28 de 2017).
} 
pero si el pago de la prestación asegurada exige, como presupuesto sustantivo, la demostración del siniestro y la cuantía de la pérdida, es claro que el cumplimiento de esta carga simplemente traduce la observancia de dicha conducta.

b. La segunda, porque al interpretar una norma jurídica es necesario tener en cuenta, en todos los casos, el efecto útil de la misma.

Quiere ello decir que, entre varias interpretaciones plausibles, el juez debe preferir la que le brinde mayor eficacia a la disposición interpretada, por sobre la que se lo restrinja, máxime si en ella se reconoce un determinado derecho.

Desde esta perspectiva, considerar que la reclamación hace las veces de requerimiento con fines interruptores de la prescripción, da lugar a que la facultad prevista en el inciso final del art. 94 del C.G.P. resulte, en la práctica, anodina, porque en un solo acto quedarían agrupadas la demostración del derecho (de suyo esencial) y la interrupción del término para ejercerlo. Expresado con otras palabras, como esta modalidad de interrupción sólo puede darse por una vez, no es posible aceptar una postura en virtud de la cual la carga de presentar una reclamación absorbe el derecho del acreedor a exigirle a su deudor, con fines interruptores de prescripción, que honre una deuda cuyas variables -siniestro y cuantía de pérdida-previamente debe probar" (Destacado fuera del texto original).

En concordancia con lo anterior, tampoco es de recibo la posición sostenida, aunque de forma moderada, por el Tribunal Arbitral que resolvió la controversia existente entre el Instituto de Seguro Sociales - ISS (en liquidación) y La Previsora S.A. Compañía de Seguros mediante laudo del 08 de octubre de 2015, en la medida en que aún cuando con la reclamación se acredite clara e inequívocamente el derecho a la indemnización, así como su magnitud, conforme a lo requerido por el art. 1077 del Código de Comercio, ello constituye simple y llanamente el cumplimiento de una carga, más no el ejercicio del derecho que, en virtud del art. 94 del Código General del Proceso, detenta el acreedor de interrumpir la prescripción, situación que resulta aún más clara si se toma en consideración que el requerimiento escrito exige una manifestación clara e inequívoca de la parte de la relación contractual que puede ejercer esta, frente a la intención de interrumpir el computo prescriptivo.

\section{CONSIDERACIONES ADICIONALES ENTORNO A LA CONFIGURACIÓN Y CÓMPUTO DE LA PRESCRIPCIÓN EN EL CONTRATO DE SEGURO}

\subsection{Aplicabilidad de la prescripción a los sistemas de delimitación temporal "Claims Made"y "pordescubrimiento"}

Con ocasión de la expedición de la Ley Nº 389 de 1997 el legislador autorizó la comercialización de seguros bajo las modalidades de delimitación de cobertura "Claims Made" y "por descubrimiento", según se trate de seguros de responsabilidad civil o de seguros de manejo y riesgos financieros, respectivamente, cambiando con ello el hecho constitutivo del siniestro para los contratos instrumentalizados bajo esta moda- 
$\operatorname{lidad}^{41}$. En efecto, dispuso el legislador expresamente en el art. $4^{\circ}$ del cuerpo normativo en cuestión que:

"Art. $\mathbf{4}^{\text {}}$. En el seguro de manejo y riesgos financieros y en el de responsabilidad la cobertura podrá circunscribirse al descubrimiento de pérdidas durante la vigencia, en el primero, y a las reclamaciones formuladas por el damnificado al asegurado o a la compañía durante la vigencia, en el segundo, así se trate de hechos ocurridos con anterioridad a su iniciación.

Así mismo, se podrá definir como cubiertos los hechos que acaezcan durante la vigencia del seguro de responsabilidad siempre que la reclamación del damnificado al asegurado o al asegurador se efectúe dentro del término estipulado en el contrato, el cual no será inferior a dos años".

En relación con la norma transcrita y sus implicaciones, la doctrina ha sido pacifica en aceptar que en los los seguros de riesgos financieros y manejo instrumentalizados bajo la modalidad de delimitación temporal por descubrimiento el siniestro se encuentra constituido por el conocimiento por parte del asegurado de la verificación de una pérdida (descubrimiento), siendo este el momento a partir del cual principia a computarse la prescripción conforme a lo dispuesto en el art. 1081 del Código de Comercio.

Por el contrario, subsiste en la práctica discusión entorno a si en el sistema de reclamación se presentó un cambio en la noción de siniestro, puesto que tal y como lo manifestó el Tribunal Arbitral conformado por Carmenza Mejía Martínez, Juan Carlos Esguerra Portocarrero y Juan Manuel Díaz Granados en el laudo del 04 de noviembre de 2014 mediante el cual se resolvió la controversia entre Proyectar Valores S.A. Comisionista de Bolsa en Liquidación Forzosa Administrativa contra Chubb de Colombia Compañía de Seguros S.A: y Chartis Seguros Colombia S.A. (al momento del laudo AIG Seguros Colombia S.A., hoy SBS Seguros Colombia S.A.):

"Debe puntualizarse que en la doctrina se discute si en el sistema de reclamación hay o no un cambio de la noción de siniestro. Algunos opinan que el siniestro sigue siendo el hecho dañoso [Ordóñez], mientras otros entienden que el siniestro bajo esa modalidad es la reclamación [Jaramillo]. A nivel jurisprudencial, la Corte Suprema de Justicia, Sala de Casación Civil, se inclina por aceptar que en la modalidad claims made el siniestro es la reclamación [Fallo del 18 de diciembre de 2013 M.P. Fernando Giraldo Gutiérrez]. Al margen de la discusión enunciada lo cierto es que la reclamación es el elemento que activa la cobertura y determina los cómputos respectivos. Ahora bien, la Ley N 389 de 1997 no define lo que debe entenderse por reclamación. Solo exige que sea una reclamación de la víctima en contra del asegurado o del asegurador. Por esta razón es usual que las pólizas incorporen definiciones de reclamación, las cuales han sido aplicadas sin que su validez haya sido discutida".

Pese a la existencia de la aludida discusión doctrinaria puesta de presente por el Tribunal de la referencia, es nuestro entender que para los seguros instrumentalizados bajo la modalidad Claims Made:

\footnotetext{
${ }^{41}$ IsAZa Posse, María Cristina. Algunos aspectos relacionados con el seguro de responsabilidad civil para directores y administradores D\&O, en Colombia. Revista Ibero Latinoamericana de Seguros, Vol. 31, Núm. 18. 2009. At. 33., p. 38.
} 


\begin{abstract}
“(...) el riesgo asegurable en modalidad se circunscribe a la reclamación, la cual obviamente habrá de presentarse durante la vigencia. En consecuencia, la noción de siniestro de responsabilidad igualmente cambia, a pesar de la contradicción que se genera frente al artículo 1131 del Código de Comercio, el cual dispone que el siniestro, se entenderá ocurrido, cuando acaezca el hecho externo imputable al asegurado. Este precepto debe entenderse en su versión original para la modalidad de ocurrencia, ya explicada; pero para la nueva modalidad de reclamación existe una norma especial y posterior cuya aplicación prevalece cuando los contratantes acuerden la reclamación como esquema. La congruencia exige que un concepto se considere siniestro tanto para exigir que el fenómeno se presente durante la vigencia como para efectos de la prescripción. (...) No tendría ninguna lógica decir que para la primera es la reclamación y para la segunda es la ocurrencia del hecho o viceversa.
\end{abstract}

Gústenos o no, la ley establece una figura en la cual el riesgo -y por lo mismo el siniestro- es la reclamación para todos los efectos. En consecuencia, el artículo 1131 habrá de interpretarse armónicamente con la nueva Ley Nº 389 de 1997, de manera que la prescripción operará así: Respecto de la víctima, la prescripción iniciará su cómputo desde la reclamación, que es el siniestro en esta modalidad y que debe presentarse durante la vigencia. No se computará desde la ocurrencia del hecho, dado que no es el siniestro y, de hacerlo, probablemente por ser anterior puede consumarse la prescripción previamente a la reclamación, lo cual es una conclusión absurda. Respecto del asegurado, no se presenta ninguna inquietud, ya que tanto en la modalidad de ocurrencia como en la de reclamación la prescripción corre desde el momento de la reclamación de la víctima" ${ }^{\prime 2}$.

De allí que resulte forzoso entender que en tratándose de seguros de responsabilidad civil instrumentalizados por reclamación la prescripción frente a la víctima:

“(...) debe comenzar a correr a partir de la reclamación y no del '[...] hecho externo imputable al asegurado', se insiste, porque cuando se estructuró este artículo (1990), el sistema en comentario no tenía aún carta de ciudadanía legal, lo que aconteció más de un lustro después. En tal caso la reclamación, de cara a las llamadas cláusulas claims made, sería el punto de partida de la prescripción, tanto para la víctima, como para el asegurado, respecto al asegurador, lo cual, tiene un sentido uniformador"43.

\title{
2.2. Breves consideraciones en torno a la posibilidad de renuncia la prescripción
}

Continuando con la exposición del tema bajo análisis, es importante resaltar que, a la luz de lo dispuesto en el art. 2514 del Código Civil, la prescripción:

“(...) puede ser renunciada expresa o tácitamente; pero sólo después de cumplida. Renunciase tácitamente, cuando el que puede alegarla manifiesta por un hecho suyo que reconoce el derecho del dueño o del acreedor; por ejemplo, cuando cumplidas las condiciones legales de la prescripción, el poseedor de la cosa la toma en arriendo, o el que debe dinero paga intereses o pide plazos".

\footnotetext{
${ }^{42}$ Díaz-Granados, Juan Manuel. El seguro de responsabilidad. Ed. Universidad del Rosario y Pontificia Universidad Javeriana. (2012), pp. 300-301.

${ }^{43}$ Jaramillo Jaramillo, Carlos Ignacio. Derecho de Seguros. Ed. Temis - Pontificia Universidad Javeriana. (2011), pp. 379-380.
} 
A partir de lo dispuesto en el artículo precitado sostiene el Dr. José Armando BonIVENTO JiMÉNEZ, que sólo cabe la renuncia:

“(...) a la prescripción por el deudor que se beneficiaria con ella, pero solo después de cumplida (...) combinando en esta forma algún componente de libertad para el extremo pasivo de la obligación, que puede tener razones para no alegarla, con la concepción tradicional de que las normas sobre prescripción (...) suelen considerarse como de orden público, lo que restringe la posibilidad de disposición anticipada de esa facultad a renunciar; es que, al final, admitir la renuncia a la prescripción, después de cumplida, resulta coherente con la idea del tránsito que haría la obligación, de civil a natural, si el fenómeno no prescriptivo produjere sus efectos de extinción, y como natural (...) el deudor podría ejecutar la prestación debida, vale decir, pagarla, como acto jurídico legítimo y vinculante.

Otra vez, ahora en medio de la restricción sobre el momento a partir del cual procede la renuncia a la prescripción, el inciso segundo del citado art. 2514 habilita que a ello pueda proceder el deudor en forma expresa, o de manera tácita.

Así concebida la posibilidad de renuncia a la prescripción, nótese que su regulación se acompasa con el marco normativo general que la informa, consignado en el art. 15 del Código Civil, a la luz del cual: Podrán renunciarse los derechos conferidos por las leyes, con tal que solo miren el interés individual del renunciante, y que no esté prohibida la renuncia" ${ }^{\prime 4}$.

En este sentido, bajo una interpretación armónica de los arts. 822, 1081 y 1131 del Código de Comercio, así como de los arts. 15 y 2514 del Código Civil, resulta claro que la prescripción de las acciones derivadas del contrato de seguro y las normas que lo regulan sólo puede ser renunciada por el interesado que se beneficia de la misma, una vez que se han cumplido los plazos dispuesto para tal fin en la ley ${ }^{45}$.

De allí que, tal y como lo decidió el Tribunal Arbitral de Distral S.A. (EMA) General Electric Canada Inc. Contra La Nacional Compañía de Seguros Generales de Colombia S.A., mediante el laudo del 16 de agosto de 1995 suscrito por lo árbitros Jorge Vélez García, Juan Carlos Esguerra Portocarrero y Antonio José de Irisarri Restrepo, al estudiar un caso en el cual la aseguradora había dado a entender mediante una carta al asegurado que una vez configurada la prescripción se abstendría de alegar la misma que:

“(...) la modificación de los términos de la prescripción por las partes está prohibida por el art. 1081 in fine del Código de Comercio y la renuncia al ejercicio de la excepción prescriptiva, es decir la renuncia a la prescripción, solo habría tenido validez, y por ende eficacia jurídica, si se hubiera producido después de cumplida, es decir, de consolidada en el tiempo, según lo dispone la primera parte del art. 2514 del Código Civil. Acontece en este caso que el compromiso de no proponer la excepción prescriptiva, expresado prematuramente, es decir antes de su cumplimiento, ni siquiera puede tomarse como un conato de modificación de los términos de la prescripción (ampliación, disminución, suspensión o interrupción), porque la ley perentoriamente lo prohíbe. Y, obviamente, una manifestación de voluntad, sin validez ni eficacia jurídica de ninguna clase, bien podía ser retirada o revocada".

\footnotetext{
${ }^{44}$ Bonivento JimÉnez, José Armando. Obligaciones. Ed. Legis. (2017), pp. 486-487.

${ }^{45}$ Barrera, Carlos Darío. Las obligaciones en el derecho moderno. Ed. Temis. (2004), p. 234.
} 
Sin perjuicio de lo anterior, es nuestro criterio, tal y como lo dilucidó el tribunal en el laudo precitado, que si bien es cierto no es posible renunciar a la prescripción ex ante a su configuración, podría caber responsabilidad en cabeza de la parte que con anterioridad a su configuración se comprometiere a no alegar la misma, en la medida que de buena fe el interesado podría desistir de interponer las respectivas acciones a la espera de que llegado el momento de hacer exigible el cumplimiento de la obligación respectiva no le sea exceptuado el cumplimiento de la misma en virtud de la configuración del fenómeno prescriptivo.

\subsection{Prescripción de la Acción e inoponibilidad de la excepción de nulidad relativa derivada de la declaración no sincera del estado de riesgo en materia de seguros}

Conforme a lo dispuesto en el art. 1058 del Código de Comercio el tomador y/o asegurado se encuentra obligado a declarar sinceramente los hechos constitutivos del estado del riesgo, so pena de incurrir en una inexactitud o reticencia que vicie de nulidad el contrato de seguro, en la medida en que los hechos no declarados sinceramente de haber sido conocidos por el asegurador le "(...) hubieren retraído de celebrar el contrato, o inducido a estipular condiciones más onerosas".

"En efecto, la legislación de seguros impone al tomador del seguro la obligación de declarar sinceramente todos los hechos y circunstancias que rodean el estado del riesgo que la compañía de seguros pretende asumir, con el propósito de que pueda conocer su extensión y pueda otorgar un consentimiento que no se encuentre errado. La declaración del estado del riesgo puede darse de dos maneras: mediante la absolución de un cuestionario que la aseguradora suministre en el cual se formulan preguntas específicas, o bien a través de una declaración espontánea en la cual el tomador o asegurado informa, según su criterio, los hechos o circunstancias que rodean el riesgo; pero en uno y otro caso la declaración debe ser sincera y exacta, toda vez que la ley sanciona el desconocimiento de este precepto, así:

3.1.1 Si la declaración se hizo con sujeción a un cuestionario y las respuestas al mismo son inexactas, por cuanto son falsas o erróneas, o son reticentes, en la medida que ocultan o encubren una situación, y tales manifestaciones son relevantes para el contrato dado que los hechos sobre que versan eran o debían ser conocidos por el tomador y que de haber sido conocidos por el asegurador lo hubieran retraído de celebrar el contrato o inducido a estipular condiciones más onerosas; existe un vicio de nulidad relativa que afecta la validez del mismo.

3.1.2 Si la declaración fue espontánea, el efecto es el mismo si el tomador por culpa incurre en reticencia o inexactitud sobre hechos y circunstancias que, según un criterio objetivo (sentido común), influyen en la posibilidad de realización del siniestro.

3.1.3 Si independientemente de que la declaración sea espontánea o se consigne en un cuestionario, la reticencia o inexactitud provienen de error inculpable del tomador, esto es, aquel en el que se ha incurrido de buena fe y no obstante haber actuado con diligencia y cuidado, el contrato no se afecta en su validez pero se reduce la prestación asegurada para lograr que exista equilibrio contractual" ${ }^{\prime 4}$.

${ }_{46}$ Superintendencia Financiera de Colombia. Concepto No. 1999040521-2 (agosto 20 de 1999). 
En concordancia con lo anterior, resulta necesario mencionar que la nulidad derivada de los supuestos que anteceden se encuentra sometida al saneamiento a razón de la configuración de los términos de prescripción del art. 1081 del Código de Comercio con independencia de que sea ejercida como una acción o como una excepción. En este sentido, ha sostenido la Corte Suprema de Justicia que:

"Para determinar cabalmente el cómputo de estos términos, es preciso tener en cuenta la diversidad de acciones que surgen 'del contrato de seguro o de las disposiciones que lo rigen', pues obviamente el art. $1081 \mathrm{del} \mathrm{C}$. de Co. no está diseñado ni se agota exclusivamente frente a la indemnizatoria - o la encaminada a exigir la prestación asegurada- en manos del beneficiario del seguro, cuestión que obliga, en el marco de una cabal hermenéutica de ese precepto, establecer en cada caso concreto la naturaleza de la prestación reclamada, pues ésta ha de determinar a su turno cuál 'es el hecho que da base a la acción' (tratándose de la prescripción ordinaria) y en qué momento 'nace el respectivo derecho' (cuando se invoque la prescripción extraordinaria); desde luego que esas acciones no siempre tienen su origen en un solo hecho o acontecimiento, pues éste varía conforme al interés de su respectivo titular (tomador, asegurado, beneficiario, o asegurador), y tampoco tienen siempre su fuente en el contrato mismo de seguro, sino algunas veces en la ley, como acontece con las acciones y las excepciones de nulidad relativa, la devolución de la prima, etc. (...)

Consecuente con lo anotado, cuando se está en frente de acciones 'derivadas del contrato' como sucede con la de reconocimiento de la indemnización (o de la prestación asegurada) a que tiene derecho el beneficiario, el momento a partir del cual ha de correr contra él la prescripción ordinaria, es distinto al que ha de tenerse en cuenta para computar idéntica prescripción contra el asegurador en el supuesto de que éste, apoyado en acciones 'derivadas de la ley', demande o excepcione, según el caso, la nulidad relativa del contrato de seguro por inexactitud o reticencia del tomador en la declaración de asegurabilidad, pues en estos supuestos 'el hecho que da base a la acción' o el nacimiento del 'respectivo derecho' es necesariamente diferente.

En efecto, en el primer caso, como lo dijo la Corte en sentencia de 7 de julio de 1977 (G.J. Tomo CIV, pág. 139 ss.), el término prescriptivo ordinario correrá a partir del conocimiento -real o presunto-y el extraordinario a partir del acaecimiento del siniestro; mientras que en el segundo caso, operará a partir del momento en que el asegurador conoció o debió conocer el hecho generador de la rescisión del contrato, es decir la inexactitud o reticencia comentadas; la misma distinción es preciso hacer, en el ejemplo referido, respecto del término prescriptivo extraordinario, porque, en el primer caso, ese término correrá contra el asegurado demandante a partir del acaecimiento del siniestro, cual lo precisó igualmente esta Corporación en la sentencia señalada; mientras que, en el segundo caso, los cinco años con los que se consuma dicha prescripción extraordinaria correrán contra el asegurador desde la fecha de materialización de la inexactitud o reticencia que, en sede contractual, será estrictamente aquella en la cual se perfeccione el contrato viciado por la mediación de tales irregularidades, llamadas a eclipsar el asentimiento de la entidad aseguradora que, aun cuando ontológicamente son anteriores, no puede perderse de vista que el derecho a impugnarlo, surge luego de su celebración, de suerte que con antelación, en puridad, no hay aún contrato y, por sustracción de materia, nada que atacar. Al fin y al cabo, dicha acción persigue impugnar la eficacia de un negocio jurídico previamente viciado. De ahí que cuando el inciso $3^{\circ}$ del art. 1.081 del Código de Comercio alude al nacimiento del respectivo derecho, hay que entender que se está refiriendo al derecho de impugnar su validez a 
través de la formulación de una acción o de una excepción orientadas a su declaratoria por el aparato judicial, lo cual supone su perfeccionamiento. Por ello es por lo que la reticencia o la inexactitud adquirirán virtualidad negocial y, por tanto, relevancia jurídica, en la medida en que efectivamente se celebre el contrato de seguro" ${ }^{47}$.

De allí que, para la Corte Suprema de Justicia, el cómputo del término para alegar la nulidad por declaración no sincera del estado del riesgo deba hacerse en íntima consonancia con lo dispuesto en el Código de Comercio en la medida que el término:

“(...) dispuesto para la prescripción ordinaria corre, pues, en relación con la acción de nulidad relativa (art. 1058 C. de Co.) del contrato de seguro, a partir del conocimiento real o presunto que tenga el titular acerca de los vicios que lo afectan, al paso que el de la extraordinaria ( 5 años) corre desde el momento que nace el derecho a demandar esa nulidad. No hay duda, entonces, de que cuando el motivo de esa acción son las reticencias o inexactitudes respecto de las manifestaciones del tomador, el interesado en promoverla debe hacerlo dentro de los dos años siguientes a la fecha en que conoció o debió conocer esas conductas, sin que en ningún caso pueda promoverla pasados cinco años desde cuando se produjo el perfeccionamiento del contrato, que dio nacimiento al derecho a demandar la rescisión, según se reseñó. Lo propio debe decirse en torno a la excepción de nulidad emergente de las citadas circunstancias, toda vez que ésta es disciplinada, igualmente, por el art. 1.081 del C. de Co., así la norma se refiera, lato sensu, a las acciones, vocablo dentro del cual, en línea de principio, deben quedar cobijadas este tipo de excepciones, pues conforme quedó expuesto en los antecedentes legislativos de la citada disposición transcritos al inicio de estas consideraciones, al vencerse el término de los cinco (5) años el asegurador ' [...] ya no podrá alegar la nulidad del contrato por vicios en la declaración de asegurabilidad' ni por vía de acción ni de excepción, se agrega" ${ }^{" 48}$.

\subsection{El cómputo de la prescripción en torno a la subrogación en materia del contrato de seguro}

Sea lo primero recordar que el art. 1096 del Código de Comercio establece que el asegurador, una vez pagada la indemnización, se encuentra legitimado para exigir del responsable del daño por vía de subrogación el resarcimiento de las sumas y erogaciones en que, con ocasión del siniestro, haya incurrido para reparar a la víctima o damnificado ${ }^{49}$, sin poder en todo caso pretender una suma mayor a la que ha desembolsado en virtud de los amparos instrumentalizados en el contrato de seguro. En efecto, esta disposición señala lo siguiente:

"Art. 1096. Subrogación del asegurador que paga la indemnización. El asegurador que pague una indemnización se subrogara, por ministerio de la ley y hasta concu-

\footnotetext{
${ }^{47}$ Corte Suprema de Justicia. Sala de Casación Civil. Proceso 5360 (M.P. Nicolás Bechara Simancas; mayo 3 de 2000).

48 Corte Suprema de Justicia. Sala de Casación Civil. Proceso 5360 (M.P. Nicolás Bechara Simancas; mayo 3 de 2000).

49 Es importante resaltar que al tenor de lo dispuesto en el artículo 1097 del Código de Comercio el asegurado tiene prohibido renunciar a sus derechos contra él o los terceros responsables del siniestro so pena de pérdida del derecho a la indemnización. De la misma forma, el asegurado se encuentra obligado a colaborar con el asegurador para el ejercicio de los derechos derivados de la subrogación conforme a lo dispuesto en el artículo 1098 del mismo cuerpo normativo.
} 
rrencia de su importe, en los derechos del asegurado contra las personas responsables del siniestro. Pero éstas podrán oponer al asegurador las mismas excepciones que pudieren hacer valer contra el damnificado.

Habrá también lugar a la subrogación en los derechos del asegurado cuando éste, a titulo de acreedor, ha contratado el seguro para proteger su derecho real sobre la cosa asegurada".

A partir de la interpretación que la Doctrina y la Jurisprudencia han realizado de la disposición normativa transcrita se tiene que para que opere la subrogación Ipso Iure se requiere que: i) el pago de la indemnización se haya dado con ocasión de un contrato de seguro válido, ii) por un hecho susceptible de ser amparado bajo el mismo, no siendo por lo tanto procedente ejercer la subrogación con ocasión de un pago ex gratia por razones comerciales; iii) que no exista prohibición legal de llevar acabo la misma, tal y como es el caso de las limitaciones a dicha figura dispuestas en los arts. 1099 y 1139 del Código de Comercio en relación con los parientes del asegurado y los seguros de personas respectivamente ${ }^{50}$; y iv) "que una vez ocurrido el siniestro surja para el asegurado una acción contra el responsable" ${ }^{51}$.

Es precisamente con ocasión de la necesidad de la acción en cabeza del asegurado que surge la discusión, para nada pacífica entre la doctrina y la jurisprudencia, consistente en si se consuma la prescripción:

“(...) según el término de prescripción de la obligación solventada por el asegurador o si, por el contrario, debe darse aplicación al art. 1081 ibídem y aplicársele en consecuencia el término de dos o cinco años previstos en el (...) discusión que no existiría si en la norma del Código de Comercio no se estableciera claramente que el término de prescripción se aplica a "las acciones que se derivan del contrato de seguro o de las disposiciones que lo rigen" ${ }^{52}$.

Frente al particular, ha sostenido la Corte Suprema de Justicia ${ }^{53}$ con apoyo en la opinión del Dr. J. Efrén Ossa, que:

“(...) si el derecho del asegurado a ser resarcido por el victimario es idéntico al que se radica en el asegurador por obra de la subrogación, también lo es la acción mediante la cual puede hacerlo valer, ya que esa es consecuencia del principio de identidad anotado, que se produce, además, como efecto propio del instituto jurídico por el cual se engendra la sustitución de un acreedor a otro, dado que en los términos del art. 1670 del Código Civil, con independencia de su origen convencional o legal la subrogación traspasa al nuevo acreedor todos los derechos, acciones y privilegios, prendas e hipotecas del antiguo, así contra el deudor principal como contra cualesquiera terceros, obligados solidaria y subsidiariamente a la deuda, de modo que al producirse la transferencia tanto de los derechos del primitivo acreedor, como de las acciones tutelares del mismo, el asegurador, como en su momento lo estaba el asegurado, queda

\footnotetext{
${ }^{50}$ López Blanco, Hernán Fabio. Comentarios al contrato de seguro. Ed. Dupre. (2010), pp. 254 y ss. y respecto a la justificación y razón de ser de la subrogación véase: HaLPERIN, Isaa. Contrato de Seguro. Ed. Depalma (1972), SolER, Roger Aleu. Seguro de Automotores. Ed: Astrea. (1978).

${ }^{51}$ Corte Suprema de Justicia. Sala de Casación Civil. (M.P. Horacio Montoya Gil; agosto 6 de 1985).

52 Barrera, Carlos Darío. Los seguros y el Derecho Civil. Ed. Facultad de Ciencias Jurídicas y Socioeconómicas. (1993), pp. 100-111.

${ }_{53}$ Corte Suprema de Justicia. Sala de Casación Civil. Proceso 1999-00206 (M.P. Jaime Alberto Arrubla Paucar; diciembre 16 de 2005).
} 
habilitado para reclamar del agente del daño el pago de la prestación debida, mediante el ejercicio de la acción de responsabilidad respectiva, derecho que, se insiste, opera dentro de la limitación cuantitativa legalmente establecida.

(...) En palabras de GARRIGUES, 'El derecho adquirido por el asegurador, a virtud de la subrogación, es un derecho derivado del que tenia el asegurado frente al tercero. Dicho en otros términos, la acción que ejerce el asegurador, contra el tercero es la misma acción que tiene el asegurado contra el autor del daño. Por esta razón gozará de todos los beneficios que esta acción tuviera $\mathrm{y}$, al contrario, quedará sometida a las mismas excepciones que podrían ser opuestas al asegurado. El plazo de prescripción será el mismo que podría ser invocado por el tercero contra la acción del asegurado', plazo que por contera no puede variar en función de la persona que lo promueve (...)

Por supuesto que el pago que da lugar al fenómeno subrogatorio previsto por el art. 1096 del estatuto comercial, tiene su causa en el negocio asegurativo. Empero, ese sólo es el presupuesto al cual se subordina legalmente el funcionamiento del instituto mencionado, por virtud del cual el asegurador sustituye al asegurado-damnificado, en los derechos y acciones que tuviere frente al responsable del daño, para obtener de él el abono de los valores indemnizados. Sin embargo, al exigir del tercero la responsabilidad que le cabe por el daño irrogado, no procura realizar un derecho dimanante del contrato de seguro, ni de su reglamentación normativa, sino el derecho al resarcimiento del cual era titular el asegurado, en su condición de víctima, derecho cuya fuente se encuentra, como ya se anotó, en la conducta antijurídica del responsable, germen también de la acción indemnizatoria respectiva (...) Como explica Ossa Gómez, 'el art. 1096 rige, en verdad, el contrato de seguro, la subrogación es su consecuencia, regula una relación adicional que, en consideración al pago de la indemnización, surge entre el asegurado y el asegurador, pero gobierna también el derecho del asegurador contra el responsable del siniestro que es extraño al contrato y cuya obligación indemnizatoria no tiene por qué cambiar de contenido, ni sus modalidades legales. El art. 1081, con su régimen de prescripción, versa sobre las acciones a que da origen el seguro y no sobre las que derivan del hecho ilícito'".

No obstante los anteriores argumentos, la posición asumida por la Corte Suprema de Justicia resulta cuando menos cuestionable en la medida que, tal y como se ha puesto de presente, el art. 1081 del Código de Comercio señala claramente que los términos de prescripción allí dispuestos se aplican tanto a las acciones que derivan del contrato de seguro, como a las que se derivan de las disposiciones que lo rigen, siendo este el caso de la subrogación dispuesta en el articulo 1096 del Código de Comercio. En efecto, tal y como lo ha sostenido de larga data un importante sector de la doctrina, toda vez que la subrogación en materia del contrato de seguro tiene un origen legal y, por lo tanto, se deriva de una norma que rige dicha tipología de negocio jurídico debería aplicársele la prescripción especial dispuesta por el legislador, por varias razones:

"La primera, porque resulta indudable que el Código de Comercio quiso de manera inequívoca extender la prescripción del art. 1081 a cualquier acción que de alguna manera proviniera del contrato de seguros. Ello es aún más claro si se tiene en cuenta que los redactores de la norma, expresamente manifestaron su intención de hacer omnicomprensivo este tratamiento de la prescripción a 'todas las acciones que se produjeran con ocasión del contrato de seguros'.

La segunda, porque parece claro que la subrogación legal es una ventaja que la ley le concede al asegurador, y si goza de esa prebenda por ser quien es, parece lógico que 
también lo perjudiquen las desventajas que ello apareja, una de las cuales seria la de una prescripción corta" ${ }^{54}$.

\section{APROXIMACIÓN A OTROS ASPECTOS RELEVANTES DE LA PRESCRIPCIÓN EN MATERIA DE SEGUROS}

\subsection{Norma especial para el cómputo de la prescripción al interior de los procesos de responsabilidad fiscal}

Sea lo primero recordar que el proceso de responsabilidad fiscal, conforme a lo dispuesto en el articulo $4^{\circ}$ de la Ley $\mathrm{N}^{\circ} 610$ de 2000, tiene como finalidad el

“(...) resarcimiento de los daños ocasionados al patrimonio público como consecuencia de la conducta dolosa o culposa de quienes realizan gestión fiscal mediante al pago de una indemnización pecuniaria que compense el perjuicio sufrido por la respectiva entidad estatal". De allí que, el art. $1^{\circ}$ del mentado cuerpo normativo, conciba al proceso de responsabilidad fiscal como el "(...) conjunto de actuaciones administrativas adelantadas por las Contralorías con el fin de determinar y establecer la responsabilidad de los servidores públicos y de los particulares, cuando en el ejercicio de la gestión fiscal o con ocasión de ésta, causen por acción u omisión y en forma dolosa o culposa un daño al patrimonio del Estado".

En relación con las características o elementos de la responsabilidad fiscal y el proceso de responsabilidad fiscal, a la luz de lo dispuesto en la Ley $\mathrm{N}^{\circ} 610$ de 2000 y la Ley $\mathrm{N}^{\circ} 1474$ de 2011, se tiene que esta tipología de responsabilidad es de naturaleza calificada en al medida que tal y como lo dispone el art. $3^{\circ}$ de la Ley $\mathrm{N}^{\circ} 610$ de $2000 \mathrm{el}$ tipo de conducta cuyo enjuiciamiento se persigue sólo puede predicarse de los servidores públicos y particulares que en ejercicio de la gestión fiscal causen un detrimento patrimonial al estado ${ }^{55}$.

A su vez, se trata de una responsabilidad eminentemente subjetivamente toda vez que tal y como se desprende del art. 118 de la Ley $\mathrm{N}^{\circ} 1474$ de 2011 para que exista responsabilidad fiscal se requiere la conducta incurrida por el gestor fiscal encaje dentro del dolo o la culpa grave, en la medida que conforme al art. $90^{56}$ superior, la Corte Constitucional ha estimado que:

“(...) si bien hay lugar a declarar la responsabilidad patrimonial del Estado (por intermedio de los órganos con personería jurídica que lo representan), cuando a través de sus agentes se ha producido un daño antijurídico que le resulta imputable a éste,

\footnotetext{
${ }^{54}$ Barrera, Carlos Darío. Los seguros y el Derecho Civil. Ed. Facultad de Ciencias Jurídicas y Socioeconómicas. (1993), p. 101.

55 Díaz Granados, Juan Manuel. La responsabilidad fiscal y su incidencia en los seguros. Revista Ibero Latinoamericana de Seguros, Vol. 40, Núm. 23. 2014. At.161., p. 170.

56 Artículo 90. El Estado responderá patrimonialmente por los daños antijuridicos que le sean imputables, causados por la acción o la omisión de las autoridades públicas. En el evento de ser condenado el Estado a la reparación patrimonial de uno de tales daños, que haya sido consecuencia de la conducta dolosa o gravemente culposa de un agente suyo, aquél deberá repetir contra éste (Subrayado y negrillas propias).
} 
también es claro que dichos agentes están obligados a indemnizar al Estado, en los casos en que la condena impuesta a la Administración por parte del juez contencioso ha sido consecuencia de una "conducta en la que concurre la especial calificación prevista por el constituyente: dolosa o gravemente culposa" ${ }^{57}$ (Destacado fuera del texto original).

Es necesario destacar que el proceso de responsabilidad fiscal es de naturaleza particularmente patrimonial en la medida en que con él se busca resarcir un daño causado al patrimonio estatal y por lo tanto se encuentra desprovisto de toda naturaleza sancionatoria o penal, lo que por demás lo convierte en un proceso de naturaleza independiente y autónoma en relación con cualquier otro tipo de responsabilidad o proceso, tal y como sería el caso de la acción de repetición derivada de la responsabilidad personal del servidor público. ${ }^{58}$

De allí que, la particular naturaleza del proceso de responsabilidad fiscal, haga necesaria, tal y como se sigue del art. 44 de la Ley $N^{\circ} 610$ de $2000^{59}$, la vinculación de la compañía aseguradora que ha amparado al presunto responsable fiscal, los bienes o el contrato sobre los cuales recaiga el objeto del proceso. Dicha vinculación, se encuentra en todo caso delimitada, tal y como lo han sostenido tanto el Consejo de Estado ${ }^{60}$ como la Corte Constitucional, por:

“(...) el riesgo amparado, en estos casos la afectación de patrimonio público por el incumplimiento de las obligaciones del contrato, la conducta de los servidores públicos y los bienes amparados, pues de lo contrario la norma acusada resultaría desproporcionada si comprendiera el deber para las compañías de seguros de garantizar riesgos no amparados por ellas" "61 (Destacado fuera del texto original).

Lo anterior resulta aún más notorio si se toma en consideración que tal y como lo ha manifestado la doctrina:

“(...) el contrato de seguro no se altera en su alcance $y$ particularidades por el hecho de que exista un proceso de responsabilidad fiscal. Lo primero es que el riesgo asegurado es el que se define en la póliza. Sobre el particular el art. 1054 del Código de Comercio preceptúa el riesgo es el suceso incierto que no depende exclusivamente de la voluntad del tomador, del asegurado o del beneficiario, y cuya realización da origen a la obligación del asegurador. Por su parte, el art. 1056 del Código de Comercio indica que el asegurador podrá asumir a su arbitrio todos o algunos de los riesgos a que estén expuestos el interés o la cosa asegurada.

De manera complementaria el art. 1072 del mismo código establece que el siniestro,

\footnotetext{
57 Corte Constitucional de Colombia. Sentencia C-285 de 2002 (M.P. Jaime Córdoba Triviño: abril 23 de 2002).

58 Díaz Granados, Juan Manuel. La responsabilidad fiscal su incidencia en los seguros. Memorias del XXVII Encuentro Nacional Acoldese. 2014. At. 161., pp. 168-170.

${ }^{59}$ Artículo 44. Vinculación del garante. Cuando el presunto responsable, o el bien o contrato sobre el cual recaiga el objeto del proceso se encuentren amparados por una póliza, se vinculará al proceso a la compañía de seguros, en calidad de tercero civilmente responsable, en cuya virtud tendrá los mismos derechos y facultades del principal implicado.

${ }^{60}$ Consejo de Estado. Sala de lo Contencioso Administrativo. Sección Quinta. Proceso 2010-00612. (C.P. Alberto Yepes Barreiro; febrero 22 de 2018).

${ }^{61}$ Corte Constitucional de Colombia. Sentencia C-648 de 2002 (M.P Jaime Córdoba Triviño: Agosto 13 de agosto de 2002).
} 
que da lugar al nacimiento de la obligación a cargo del asegurador, es la realización del riesgo asegurado. Así las cosas, el contrato de seguro cubrirá únicamente aquellos eventos que se enmarquen en la definición de riesgo asegurado y las Contralorías deben aplicarlo de manera estricta. Igual acontece con las sumas aseguradas, límites y sublimitas (art. 1079), deducibles (art. 1103), garantías (art. 1061), etc. (...)

Indudablemente, las Contralorías tienen la facultad de establecer la responsabilidad fiscal de los gestores fiscales y de condenar a las compañías de seguros con base en las pólizas de seguros que tengan relación con el caso. Tal condena, se repite, no es a título de responsables fiscales, sino como garantes y en las mismas debe respetarse el respectivo contrato de seguro" ${ }^{\prime 2}$ (Destacado fuera de texto original).

Conforme se desprende de las citas antecedentes, resulta claro que las compañías de seguros pueden ser vinculadas a procesos de responsabilidad fiscal, bajo la figura de terceros civilmente responsables, aún cuando no detentan el carácter de gestores fiscales y por lo tanto no puedan ser consideradas como fiscalmente responsables. Se destaca igualmente a partir de lo anterior que las aseguradoras así vinculadas tampoco pueden entenderse como codeudoras solidarias de los presuntos responsables fiscales, máxime cuando el alcance de su responsabilidad como tercero llamado a responder se encuentra limitado en forma precisa por los términos y condiciones que se encuentren pactados en el contrato de seguro, es decir, dependerá del interés asegurado y el riesgo asegurado que marcan el objeto y causa del contrato de seguro y, muy especialmente, a los precisos amparos y exclusiones, así como los límites y demás condiciones que fueron pactados en la póliza expedida por la aseguradora, que son, en últimas, los que determinarán el alcance de la protección brindada por el contrato de seguro como mecanismo contractual de traslación de riesgos. Así las cosas, la obligación del garante no coincide necesariamente o, lo que es lo mismo no tiene la misma extensión y alcance en todos los casos que la del responsable fiscal o principal obligado.

Ahora bien, la vinculación de una aseguradora como tercero civilmente responsable se encuentra igualmente limitada por la prescripción de las acciones del contrato de seguro especialmente regulado en materia de responsabilidad fiscal en el art. $9^{\circ}$ de la Ley $\mathrm{N}^{\circ} 610$ de 200, de conformidad con la expresa remisión realizada frente al particular por el art. 120 de la Ley $\mathrm{N}^{\circ} 1474$ de 2011, siendo de la mayor importancia resaltar que la última de estas normas, en ninguno de sus apartados, se refiere a la caducidad, sino únicamente a la prescripción.

En efecto, tal y como lo dispone el texto del art. 120 de la Ley $\mathrm{N}^{\circ} 1474$, es claro que: "Las pólizas de seguros por las cuales se vincule al proceso de responsabilidad fiscal al garante en calidad de tercero civilmente responsable prescribirán en los plazos previstos en el art. 9o de la Ley N 610 de 2000" (Destacado fuera de texto original). En relación con lo cual resulta de la mayor importancia esclarecer que al tenor del art. $9^{\circ}$ de la Ley $\mathrm{N}^{\circ} 610$ de 2000 (modificado mediante el art. 127 del Decreto 403 de 2020) es claro que:

62 Díaz Granados, Juan Manuel. La responsabilidad fiscal y su incidencia en los seguros. Revista Ibero Latinoamericana de Seguros, Vol. 40, Núm. 23. 2014. At.161., p. 130. 


\begin{abstract}
“Art. 9. Caducidad y prescripción. La acción fiscal caducará si transcurridos diez (10) años desde la ocurrencia del hecho generador del daño al patrimonio público, no se ha proferido auto de apertura del proceso de responsabilidad fiscal. Una vez proferido el auto de apertura se entenderá interrumpido el término de caducidad de la acción fiscal.
\end{abstract}

Este término empezará a contarse para los hecho o actos instantáneos desde el día de su realización, y para los complejos, de tracto sucesivo, de carácter permanente o continuado desde la del último hecho o acto.

La responsabilidad fiscal prescribirá en cinco (5) años, contados a partir de la expedición del auto de apertura del proceso de responsabilidad fiscal, si dentro de dicho término no se ha dictado providencia en firme que la declare (...)".

Corolario de lo anterior, la prescripción de las acciones para hacer efectivas las pólizas de seguro, en materia de responsabilidad fiscal, sigue el plazo de cinco (5) años dispuesto en el mentado art. 9 de la Ley $\mathrm{N}^{\circ} 610$ de 2000 en la medida en que el término de prescripción no fue alterado con ocasión del Decreto 403 de 2020. Razón por la cual, atendiendo a la interpretación armónica y en conjunto de las normas citadas, la prescripción del contrato de seguro en los procesos de responsabilidad fiscal sólo operará conforme a las reglas de la prescripción una vez transcurridos cinco (5) años desde la exigibilidad de la obligación.

Nótese que si bien con ocasión del art. 127 del Decreto 403 de 2020 no se realizó modificación alguna al término de prescripción del art. $9^{\circ}$ de la Ley $\mathrm{N}^{\circ} 610$ de 2000, al cual hace remisión el art. 120 de la Ley $N^{\circ} 1474$ de 2011 para fijar el término de prescripción del contrato de seguro en materia de responsabilidad fiscal, existe la posibilidad que, tal y como sucedió con anterioridad a la entrada en vigencia de la Ley $\mathrm{N}^{\circ}$ 1474 de 2011 con la desaplicación de los arts. 1081 y 1131 del Código de Comercio al proceso de responsabilidad fiscal por parte del Consejo de Estado, entiendan tanto el órgano de control como la rama judicial que, al establecerse una prescripción de las acciones derivadas del contrato de seguro disímil e inferior al término de caducidad, se torna en inane la finalidad de los amparos contratados, procediendo a establecer con ocasión de ello vía jurisprudencial, pese a la literalidad de las disposiciones precitadas, que el contrato de seguro en materia de responsabilidad fiscal prescribe en el termino dispuesto para la caducidad de la acción en el art. $9^{\circ}$ de la Ley $\mathrm{N}^{\circ} 610$ de 2000.

Lo anterior, parece aún más plausible si se toma en consideración que el Consejo de Estado sostuvo con ocasión de la determinación de la norma aplicable entre el art. $9^{\circ}$ de la Ley $\mathrm{N}^{\circ} 610$ de 2000 y el Código de Comercio para computar la prescripción del contrato de seguro, con anterioridad a la promulgación de la Ley $\mathrm{N}^{\circ} 1474$ de 2011, lo siguiente:

"5.2 La postura jurisprudencial de la Sección Primera del Consejo de Estado, torna inane el contrato de seguro, pues en la práctica ello implicaría que la contraloría no contaría con los 5 años que le otorga la ley ibídem, sino que debería adoptar una decisión en el lapso de 2 años, so pena de que la póliza de seguros prescriba. Lo que es bastante poco probable que ocurra.

Este razonamiento, no solo pone en riesgo el control fiscal que en lugar de fortalecerse por la existencia de la póliza se ve, paradójicamente, debilitado, pues las contralorías, contrario al mandato de la Ley $N^{\circ} 610$, deberán expedir una deci- 
sión antes de 2 años, so pena de que la garantía que se contrató, precisamente, para resarcir el daño causado, se declare 'prescrita'.

En otras palabras, no tendría sentido que las entidades públicas contraten pólizas de seguros para tratar de mitigar los riegos derivados de la declaratoria de responsabilidad fiscal, pues casi siempre la decisión se proferiría cuando aquella esté prescrita y la finalidad que tuvo al celebrar dicho negocio jurídico se desdibujaría. pues solo se lograría si el ente fiscal profiere una decisión supremamente rápida.

$\underline{\text { Si esto es así, claramente la vinculación de las aseguradoras, lejos de cumplir el papel }}$ de garantes que se les otorgó en virtud del contrato, se tornaría como un obstáculo para el ente de control fiscal que se vería compelido a adoptar decisiones en un tiempo muy corto en comparación con los procedimientos en los que no sea necesario llamar a una compañía de seguros.

Entonces ¿para qué contratar un seguro si cuando aquel se quiera hacer efectivo ya estará prescrito? ¿Vale la pena realmente que se contrate un seguro para amparar la responsabilidad fiscal de los servidores públicos derivada de manejos inadecuados? Estos cuestionamientos, evidencian que la posición jurisprudencial vigente no es sólida" ${ }^{63}$ (Destacado fuera del texto original).

\subsection{Imprescriptibilidad del seguro previsional}

Sea lo primero recordar que el seguro previsional es aquel por medio del cual se pretende garantizar el capital suficiente para financiar la pensión de invalidez o de supervivencia que se causa a favor del cotizante o sus beneficiarios, integrando para todos los efectos al mismo de acuerdo a lo dispuesto en la Ley $\mathrm{N}^{\circ} 100$ de 1993 los valores correspondientes a los aportes obligatorios y el bono pensional, si lo hubiere, en la cuenta de ahorro individual. De allí que tal y como lo ha sostenido la Superintendencia Financiera de Colombia ${ }^{64}$ con fundamento en lo dispuesto en los arts. 20, 59, 60, 70, 77 y 108 de la Ley $\mathrm{N}^{\circ} 100$ de 1993, así como con ocasión de lo dispuesto en los Decretos No. 876 y No. 1161 de 1994, el Capitulo II numeral 3.2. de la Circular Externa Básica Jurídica No. 007 de 1996, que:

“(...) la prestación a cargo de las aseguradoras en el Régimen de Ahorro Individual con Solidaridad, constituye un componente de las pensiones de invalidez y sobrevivencia, en la medida en que se concreta el pago de la suma adicional requerida para completar el capital que financie el monto de pensión, recibiendo como contraprestación, una prima proveniente del ingreso base de cotización de los afiliados al sistema. Para tal efecto, la normativa propia del régimen de seguridad social en pensiones estableció las condiciones bajo las cuales opera este seguro dentro del Sistema de Seguridad Social Integral.

Con la asignación de una función consistente en el cubrimiento de la denominada suma adicional para financiar las pensiones de invalidez y sobrevivencia, el legislador facultó a las aseguradoras para explotar el ramo de seguros previsionales, incorporándolas al Sistema General de Pensiones (...).

\footnotetext{
${ }^{63}$ Consejo de Estado. Sala de lo Contencioso Administrativo. Sección Quinta. Proceso Rad. 25000-23-24000-00287-02 (junio 7 de 2018).

${ }^{64}$ Superintendencia Financiera de Colombia. Concepto No. 2005061070-00 (diciembre 9 de 2005).
} 
Así las cosas, con la creación de los seguros previsionales el legislador instituyó un particular esquema de aseguramiento de los riesgos de invalidez y sobrevivencia del Régimen de Ahorro Individual con Solidaridad, que participa de los principios y reglas que informan el Sistema de Seguridad Social Integral, definido por el art. 48 de la Constitución Política de Colombia como un servicio público obligatorio ' [...] dirigido, controlado y coordinado por el Estado para salvaguardar la vida, la dignidad humana, la integridad física o moral, contra toda clase de adversidades que pongan en peligro la vida individual y social $[\ldots]^{\prime}$, en el cual los ingresos percibidos por quienes administran el sistema y participan en este, tienen la connotación de ingresos parafiscales con destinación específica".

Visto lo anterior, de cara a analizar la aplicación del fenómeno prescriptivo a dicha tipología de seguro, resulta necesario mencionar que el derecho a reclamar la pensión, de acuerdo con la jurisprudencia constitucional, se trata de un derecho imprescriptible:

“(...) con sujeción a los mandatos constitucionales consagrados en la Carta Política de 1991; basta con recordar el art. 48 constitucional que garantiza el derecho irrenunciable a la seguridad social y el 53 que obliga al pago oportuno de las pensiones.

Lo anterior, dada la naturaleza de la prestación económica y social de la cual se trata, según la cual, '[...] el derecho a pensión de jubilación o vejez, en los términos definidos por la ley, constituyen un derecho de aplicación inmediata en aquellos eventos en los cuales está destinado a suplir el mínimo vital básico de las personas de la tercera edad. Lo anterior, no sólo por su estrecha relación con el derecho al trabajo, sino porque en tratándose de personas cuya edad hace incierta una virtual vinculación laboral, su transgresión compromete la dignidad de su titular como quiera que depende de la pensión para satisfacer sus necesidades básicas" "'65.

A partir de lo anterior, ha entendido la Superintendencia Financiera de Colombia que las disposiciones contempladas en el art. 1081 del Código de Comercio en relación con la prescripción no son aplicables a los seguros previsionales en la medida en que la obligación condicional en cabeza de la aseguradora en caso de siniestro se encuentra determinada por el pago de uno de los componentes necesarios para la financiación de la pensión, por lo que siendo el derecho a exigir aquella imprescriptible, también habrá de serlo el derecho a exigir las sumas encaminadas a garantizar su consecución.

En efecto, ha sostenido la Superintendencia Financiera de Colombia ${ }^{66}$ que:

“(...) la suma adicional a cargo de la aseguradora constituye un componente necesario para financiar la pensión, debe subrayarse que la naturaleza no extintiva del derecho a su reconocimiento, se contrapone a la aplicación de un fenómeno como la prescripción de acciones del contrato de seguro. En efecto, si tenemos en cuenta que la prescripción operaría por el simple hecho de que durante cierto lapso de tiempo no se hubieren ejercitado tales acciones, los efectos de su aplicación se revierten directa e inevitablemente sobre el derecho a la pensión, el cual por el contrario tiene carácter imprescriptible en observancia de los mandatos de orden constitucional consagrados en los arts. 48 y 53 de nuestra Carta Fundamental que expresamente disponen que es un derecho irrenunciable y obligan a su pago oportuno, respectivamente.

\footnotetext{
${ }^{65}$ Corte Constitucional de Colombia. Sentencia T-658 de 1998 (M.P. Carlos Gaviria Díaz: noviembre 11 de 1998).

${ }_{66}$ Superintendencia Financiera de Colombia. Concepto No. 2005061070-00 (diciembre 9 de 2005).
} 
En otras palabras, esa contraposición entre la naturaleza inextinguible del derecho a la pensión y la institución de la prescripción de acciones del contrato comercial de seguro, jurídicamente debe resolverse dándole prevalencia al derecho de superior jerarquía, que en este caso es el derecho al reconocimiento y pago de la pensión, como expresión directa del derecho constitucional a la seguridad social.

Definida la naturaleza jurídica especial que revisten los seguros previsionales, cuyas características los hace diferentes del seguro tradicional, en criterio de esta Dirección a los mismos no les resultan aplicables en su integridad las normas del derecho privado contenidas en el Código de Comercio que regulan los seguros privados; es el caso de la prescripción de acciones contenida en su art. 1081, cuya aplicación haría nugatorio el derecho a la pensión que es de carácter imprescriptible y quebrantaría el mecanismo para el pago de pensiones que el Estado garantiza a través de la regulación examinada, en cumplimiento de los mandatos de orden constitucional antes citados".

Ahora bien, la anterior posición no ha estado exenta de críticas en la medida en que, como lo ha resaltado un sector de la doctrina, “(...) no existe una norma, contenida en la Ley $\mathrm{N}^{\circ} 100$ o en las disposiciones que la reforman o reglamentan, que de ese modo lo determine, o que, por lo menos, permita siquiera columbrar la presencia de tan extraña idea" ${ }^{67}$. No obstante, tal y como lo sostiene el Dr. Jorge Eduardo NARvÁEz BONNET $^{68}$, dicha crítica carece de validez a la luz de la supremacía constitucional en la medida en que el establecer la imprescriptibilidad de los seguros previsionales a partir de la imprescriptibilidad del derecho constitucional a la jubilación “(...) no se trata de inferir la imprescriptibilidad de las acciones derivadas del contrato de seguro por vía de interpretación extensiva, sino a través del contexto de las instituciones y de esta forma alcanzar una verdadera integración del ordenamiento", garantiza la supremacía efectiva de la constitución y los derechos en ella consagrados.

\subsection{Prescripción de la acción en materia de protección al consumidor}

Con ocasión de la expedición del Estatuto de Protección al Consumidor el legislador estableció en cabeza de diversas superintendencias, entre ellas la Superintendencia Financiera de Colombia, funciones jurisdiccionales de cara a conocer de las controversias que pudieren presentarse entre los consumidores y las entidades vigiladas ${ }^{69}$, disponiendo para ello, en el numeral $3^{\circ}$ del art. 58 de la Ley $N^{\circ} 1480$ de 2011, que el ejercicio de la acción debería realizarse a:

“(...) más tardar dentro del año siguiente a la expiración de la garantía y las controversias netamente contractuales, a más tardar dentro del año siguiente a la terminación del contrato. En los demás casos, deberán presentarse a más tardar dentro del año siguiente a que el consumidor tenga conocimiento de los hechos que motivaron la reclamación (...)" (Destacado fuera del texto original).

\footnotetext{
${ }^{67}$ Naranjo, Héctor Marín. La prescripción en los seguros previsionales en Colombia. Revista Iberoamericana de Seguros Vol. 15, Núm. 25. 2005. At. 85., p. 106.

${ }_{68}$ NARváEz Bonnet, Jorge Eduardo . La prescripción de los seguros previsionales en Colombia. Pág. 301. Revista Ibero latinoamericana de Seguros, Vol. 16, Núm. 26, pp. 259-304.

69 Jaramillo Salgado, Patricia. La protección del consumidor de seguros en Colombia: antecedentes, evolución, retos y perspectivas. Revista Ibero Latinoamericana de Seguros, Vol. 37, Núm. 21. 2012. At. 213.
} 
Frente al particular ha sido clara la Superintendencia Financiera de Colombia en Sentencia No 2017-0823, del 15 de marzo de 2018, al decir que, en virtud de lo previsto en la norma antes citada, la cual:

“(...) asignó funciones jurisdiccionales a la Superintendencia Financiera de Colombia, en controversias netamente contractuales (como las relacionadas con los depósitos en cuenta de ahorros) la demanda deberá interponerse 'a más tardar dentro del año siguiente a la terminación del contrato' ${ }^{\prime}$ Por tal razón, en los eventos en que aparezca probado que se ha superado el mencionado término, contado desde la terminación del pacto, habrá precluido la oportunidad del demandante para reclamar la tutela estatal del derecho pretendido en vía de acción de protección al consumidor ante la Delegatura para Funciones Jurisdiccionales de esta Superintendencia y así deberá declararse en cualquier estado del proceso, al tenor de lo dispuesto por el numeral $3^{\circ}$ del art. 278 del Código General del Proceso, como aconteció en este caso concreto" (Destacado fuera del texto original).

En relación con lo expuesto, resulta de particular importancia manifestar que si bien la Superintendencia Financiera de Colombia sostuvo en un primer momento que lo dispuesto por el legislador en la norma en comento se trataba de la caducidad de la acción y no de la prescripción de la misma, dicha posición fue zanjada con ocasión del fallo proferido el 21 de enero de 2016 por el Tribunal Superior de Bogotá al interior del proceso con radicado No. 11001-31-99-001-2015-01185-01 “(...) en el sentido de que el nombre o la denominación no debe ser de caducidad sino de prescripción, con las consecuencias procesales que ello conlleva" ${ }^{\text {"70 }}$. Lo anterior, se explica en la medida que, en criterio del Tribunal:

“(...) si bien es cierto, el numeral $3^{\circ}$ del art. 58 de la Ley $N^{\circ} 1480$ de 2011, al cual acudió, no hace alusión a una figura en concreto, y, por ende, podría decirse que se refiere a una caducidad de la acción, como en efecto se declaró; también lo es, que de forma posterior, específicamente en el numeral $6^{\circ}$ de la misma disposición, el legislador optó por la figura de la prescripción de la acción, regulación de índole especial que debe primar y la cual no puede ser declarada de oficio (...) debe acatarse la regulación consagrada en el art. 2513 del C.C., por expresa remisión vertida en los arts. $1^{\circ}, 2^{\circ} \mathrm{Y}$ 822 del C. de Co., en consonancia con lo reglado en el art. 305 del C. de P.C., normas también de orden y derecho público, por lo mismo, de obligatorio cumplimiento"71,

En concordancia con lo expuesto, a la luz de la jurisprudencia, resulta claro que la inacción o no interposición de la acción de protección al consumidor en el año siguiente a la terminación de la vigencia técnica del contrato de seguro trae como consecuencia la prescripción de la acción en cuestión, ello con prescindencia de la posibilidad de acudir a la vía ordinaria siempre y cuando no se hubiere configurado la prescripción por las reglas generales que rigen la materia al interior de dicha tipología de negocio jurídico.

\footnotetext{
70 Jaramillo Salgado, Patricia. La protección del consumidor de seguros en Colombia: antecedentes, evolución, retos y perspectivas. Revista Ibero Latinoamericana de Seguros, Vol. 37, Núm. 21. 2012. At. 213., p. 288.

71 Tribunal Superior de Bogotá D.C. Proceso No. 11001-31-99-001-2015-01185-01. (M.P. Marco Antonio Álvarez Gómez: enero 21 de 2016).
} 


\section{A MANERA DE CONCLUSIÓN}

Conforme a lo expuesto en el presente artículo, resulta imperativo concluir que la prescripción aplicable al contrato de seguro y las acciones derivadas de las normas que lo regulan, al tenor de lo dispuesto en el art. 1081 del Código de Comercio, hace alusión a una prescripción extintiva que, de forma particular para el ordenamiento jurídico en que se integra, posee un carácter plural y omnicomprensivo. Ello es así en la medida en que la misma disposición normativa contempla dos (2) plazos de prescripción, uno ordinario o subjetivo y otro extraordinario u objetivo, los cuales corren para todos los efectos de forma paralela aplicándose el primero de aquellos que se configure, sin que sea potestativo de los interesados determinar cual de ellos emplear en una situación determinada.

En relación con la prescripción ordinaria, se tiene que la misma se configura en un lapso de dos (2) años computado desde el momento en que el interesado -a saber el asegurador, tomador, asegurado o beneficiario-, conoció o debió conocer la ocurrencia del hecho dañoso que da base a la acción, siendo en todo caso susceptible de suspensión dicho lapso en favor de los incapaces, quienes no puedan hacer valer su derecho y, al tenor de lo dispuesto en la Ley $\mathrm{N}^{\circ} 640$ de 2001, hasta por tres (3) meses por la simple presentación de la solicitud a conciliación extrajudicial.

De igual forma, se tiene que el término relativo a la prescripción ordinaria del contrato de seguros y las acciones derivadas de las disposiciones que lo regulan es susceptible de ser interrumpido bien sea naturalmente por el reconocimiento de la obligación, bien civilmente por la radicación del escrito de demanda, siempre y cuando el auto admisorio de la misma sea notificado al extremo pasivo dentro del año siguiente a la notificación al accionante por parte del juez de conocimiento de la controversia, o por el requerimiento escrito de conformidad con lo dispuesto en el inciso final del art. 94 del Código General del Proceso.

Por su parte, la prescripción extraordinaria u objetiva se configura en un término de cinco (5) años contados desde el momento que nace el respectivo derecho, sin que importe para todos los efectos que el interesado tuviese o no conocimiento de la ocurrencia del mismo o si se encuentra o no en capacidad de ejercer la respectiva acción.

Sin perjuicio de lo expuesto, en relación con los seguros de responsabilidad civil, se tiene que la prescripción se encuentra regida por las disposiciones especiales contenidas en el art. 1131 del Código de Comercio, a partir del cual ha entendido tanto la doctrina como la jurisprudencia que la prescripción de la acción en cabeza de la victima se computa en el termino dispuesto para la prescripción extraordinaria desde el momento en que acaezca el hecho externo imputable al asegurado, mientras que, para este último, el término de la prescripción será el ordinario de dos (2) años contado a partir del momento en que la víctima le formule una petición judicial o extrajudicial de reparación. En relación con el particular, no puede dejar observarse que en aquellos seguros de responsabilidad civil instrumentalizados bajo la modalidad de delimitación temporal "Claims Made" o "por Reclamación” la prescripción de las acciones deberá computarse tanto para el asegurado, como para la víctima tomando como punto de partida la reclamación judicial u extrajudicial que este ultimo realice 
al primero en vigencia de la póliza, siempre y cuando el hecho que da base a la acción hubiese ocurrido dentro del periodo de retroactividad instrumentalizado en la póliza cuya afectación se pretenda.

No obstante lo anterior, es necesario reiterar que, en relación con las acciones derivadas del contrato de seguro, sin perjuicio de las normas ya referenciadas, el legislador dispuso términos particulares de prescripción aplicables expresamente a los procesos de protección al consumidor y los procesos de responsabilidad fiscal. En relación con el primero de estos estableció el art. 58 de la Ley $\mathrm{N}^{\circ} 1480$ de 2011 que el ejercicio de la acción debería incoarse a más tardar dentro del año siguiente a la terminación del contrato de seguro. Por su parte, en lo atinente al proceso de responsabilidad fiscal, estableció el legislador que la Contraloría contaría con un termino de cinco (5) años, conforme a lo dispuesto en los arts. $9^{\circ}$ de la Ley $\mathrm{N}^{\circ} 610$ de 2000 y 120 de la Ley $\mathrm{N}^{\circ}$ 1474 de 2011, para vincular al proceso de responsabilidad fiscal a la aseguradora como tercero civilmente responsable so pena de la configuración del fenómeno analizado.

\section{BIBLIOGRAFÍA}

\section{a. Articulos y Libros}

Arias, Antonio Emiro Thomas. Nuevo régimen de prescripción civil. Vniversitas, Vol. 52, Núm. 105. 2003. At. 211.

Barrera, Carlos Darío. Las obligaciones en el derecho moderno. Ed. Temis. (2004).

Barrera, Carlos Darío. Los seguros y el Derecho Civil. Ed. Facultad de Ciencias Jurídicas y Socioeconómicas. (1993).

Bonivento JimÉnez, José Armando. Obligaciones. Ed. Legis. (2017).

Casallas Bautista, Sonia Esperanza. ET AL. Análisis académico jurisprudencial sede jurisdiccional de protección al consumidor. Revista Ibero latinoamericana de Seguros Vol. 27. Núm. 49. julio-diciembre de 2018. At. 269.

Castro, José Fernando; Calonje Londoño, J. \& Nataly Ximena. Derecho de obligaciones: Aproximación a la praxis y a la constitucionalización. Ed. Universidad Católica de Colombia. (2015).

Collazos Rivera, Juan Camilo \& Fajardo Gutiérrez, Lucas. Prescripción en el contrato de seguro ¿tradición o modernismo? Revista Ibero latinoamericana de Seguros, Vol. 32, Núm. 19. 2010. At.73.

Díaz Granados, Juan Manuel. El seguro de responsabilidad. Ed. Universidad del Rosario y Pontificia Universidad Javeriana. (2012).

DíAz Granados, Juan Manuel. La responsabilidad fiscal su incidencia en los seguros. Memorias del XXVII Encuentro Nacional Acoldese. 2014. At. 161.

DíAz Granados, Juan Manuel. La responsabilidad fiscal y su incidencia en los seguros. Revista Ibero Latinoamericana de Seguros, Vol. 40, Núm. 23. 2014. At.161. 
DíAz Granados, Juan Manuel. Las acciones relacionadas con el seguro de responsabilidad. Revista Ibero Latinoamericana de Seguros, Vol. 28, Núm. 17. 2008. At. 67.

HalPerin, Isaac. Contrato de Seguro. Ed. Depalma (1972).

Hinestrosa Forero, Fernando. La prescripción extintiva. Ed. Universidad Externado de Colombia. (2000).

Isaza Posse, María Cristina. Algunos aspectos relacionados con el seguro de responsabilidad civil para directores y administradores $D \& O$, en Colombia. Revista Ibero Latinoamericana de Seguros, Vol. 31, Núm. 18. 2009. At. 33.

Jaramillo Jaramillo, Carlos Ignacio. Delimitación temporal de la cobertura en el Seguro de la Responsabilidad Civil - Adopción del sistema de aseguramiento comúnmente conocido como "Claims Made”. Revista Ibero Latinoamericana de Seguros, Vol. 20, Núm., 35. 2011. At. 145.

Jaramillo Jaramillo, Carlos Ignacio. Derecho de Seguros. Ed. Temis - Pontificia Universidad Javeriana. (2011).

JARAMILlo JARAmillo, Carlos Ignacio. La doctrina de los actos propios y su proyección en la esfera del derecho de los contratos. Estudios de Derecho Privado Tomo 1. Ed. Universidad del Rosario (2009).

Jaramillo Salgado, Patricia. La protección del consumidor de seguros en Colombia: antecedentes, evolución, retos y perspectivas. Revista Ibero Latinoamericana de Seguros, Vol. 37, Núm. 21. 2012. At. 213.

LóPez Blanco, Hernán Fabio. Comentarios al contrato de seguro. Ed. Dupre. (2010).

NARANJo, Héctor Marín. La prescripción en los seguros previsionales en Colombia. Revista Iberoamericana de Seguros Vol. 15, Núm. 25. 2005. At. 85.

NARVÁEz Bonnet, Jorge Eduardo . La prescripción de los seguros previsionales en Colombia. Revista Ibero latinoamericana de Seguros, Vol. 16, Núm. 26.

Ortiz Monsalve, Álvaro. Manual de obligaciones. Ed. Temis. (2013).

OSPInA Fernández, Guillermo. Régimen General de las obligaciones. Ed. Temis (2005).

Ossa Gómez, José Efrén. Teoría General del Seguro: El contrato. Ed. Temis (1991).

Ossa Gómez, José Efrén. Teoría General del Seguro: El contrato. Ed. Temis (1984).

PARRa QuiJano, Jairo. Los terceros en el proceso civil. Ed. Librería del Profesional (1989).

PÉRez Vives, Álvaro. Teoría General de las obligaciones. Ed. Universidad Nacional de Colombia (1957).

Robledo, L. La prescripción en el seguro de cumplimiento en Colombia, Revista Ibero Latinoamericana de seguros, Vol. 42, Núm. 24, (2015).

Soler, Roger Aleu. Seguro de Automotores. Ed: Astrea. (1978). 
TABARES CoRTÉs, Felipe. El evento desencadenante de la garantía de lucro cesante y el término de la prescripción ordinaria. Revista Ibero Latinoamericana de Seguros, Vol. 45, Núm. 25. 2016. At. 151.

Uribe Lozada, Nicolás. Análisis técnico-jurídico de la modalidad de cobertura por reclamación o "Claims made" en los seguros de responsabilidad civil a la luz del ordenamiento jurídico colombiano. Revista Ibero Latinoamericana de Seguros, Vol. 44, Núm. 25. 2016. At. 13.

Zornoza PRIETo, Hilda Esperanza. El seguro de Responsabilidad Civil su evolución normativa y jurisprudencial en Colombia. Revista Ibero Latinoamericana de Seguros, Vol. 35, Núm. 20. 2011. At. 85.

\section{b. Jurisprudencia}

Consejo de Estado. Sala de lo Contencioso Administrativo. Sección Quinta. Proceso Rad. 25000-23-24-000-00287-02 (junio 7 de 2018).

Consejo de Estado. Sala de lo Contencioso Administrativo. Sección Quinta. Proceso 201000612. (C.P. Alberto Yepes Barreiro; febrero 22 de 2018).

Consejo de Estado. Sala de la Contencioso Administrativo. Sección Tercera. Proceso 63861 (C.P. Marta Nubia Velásquez Rico; marzo 5 de 2020).

Corte Constitucional de Colombia. Sentencia C-597 de 1998 (M.P. Carlos Gaviria Díaz: 21 de octubre de 1998).

Corte Constitucional de Colombia. Sentencia T-658 de 1998 (M.P. Carlos Gaviria Díaz: noviembre 11 de 1998).

Corte Constitucional de Colombia. Sentencia C-285 de 2002 (M.P. Jaime Córdoba Triviño: abril 23 de 2002).

Corte Constitucional de Colombia. Sentencia C-648 de 2002 (M.P Jaime Córdoba Triviño: Agosto 13 de agosto de 2002).

Corte Constitucional de Colombia. Sentencia C-619 de 2002 (M.P. Jaime córdoba Triviño y Rodrigo Escobar Gil: agosto 8 de 2002).

Corte Constitucional de Colombia. Sentencia T-662 de 2013 (M.P. Luis Ernesto Vargas Silva: septiembre 23 de 2013).

Corte Suprema de Justicia. Sala de Casación Civil. (M.P. José María Esguerra Samper; julio 4 de 1977).

Corte Suprema de Justicia. Sala de Casación Civil. (M.P. Horacio Montoya Gil; agosto 6 de 1985).

Corte Suprema de Justicia. Sala de Casación Civil. (M.P. Alberto Ospina Botero; marzo 4 de 1989).

Corte Suprema de Justicia. Sala de Casación Civil. Proceso 5360 (M.P. Nicolás Bechara Simancas; mayo 3 de 2000). 
Corte Suprema de Justicia. Sala de Casación Civil. Proceso 1999-00206 (M.P. Jaime Alberto Arrubla Paucar; diciembre 16 de 2005).

Corte Suprema de Justicia, Sala de Casación Civil. Proceso No. 7173 (M.P. Cesar Julio Valencia Copete; febrero 10 de 2005).

Corte Suprema de Justicia. Sala de Casación Civil. Proceso 4690 (M.P. Carlos Ignacio Jarami1lo Jaramillo; junio 29 de 2007).

Corte Suprema de Justicia. Sala de Casación Civil. Proceso 2000-00428 (M.P. Jaime Alberto Arrubla Paucar; septiembre 20 de 2010).

Corte Suprema de Justicia. Sala de Casación Civil. Proceso 1999-01180 (M.P. Jaime Alberto Arrubla Paucar; Julio 11 de 2012).

Corte Suprema de Justicia. Sala de Casación Civil. Proceso SC7814-2016 (M.P. Luis Armando Tolosa Villabona; junio 15 de 2016).

Corte Suprema de Justicia. Sala de Casación Civil. Proceso STC-139482019 (M.P. Octavio Augusto Tejeiro Duque; octubre 11 de 2019).

Corte Suprema de Justicia. Sala de Casación Civil. Proceso SC-5515-2019 (M.P. Margarita Cabello Blanco; diciembre 18 de 2019).

Tribunal Superior de Bogotá D.C. Proceso 11001-31-99-001-2015-01185-01 (M.P. Julia María Botero Larrarte; enero 21 de 2016).

Tribunal Superior de Bogotá D.C. Proceso No. 11001-31-99-001-2015-01185-01. (M.P. Marco Antonio Álvarez Gómez: enero 21 de 2016).

Tribunal Superior de Bogotá D.C. Proceso 11001-31-03-019-2016-00687-01. (M.P. Marco Antonio Álvarez Gómez: septiembre 28 de 2017).

\section{c. Conceptos Superintendencia Financiera de Colombia}

Superintendencia Financiera de Colombia. Concepto No. 1999035395-2 (agosto 20 de 1999).

Superintendencia Financiera de Colombia. Concepto No. 1999040521-2 (agosto 20 de 1999).

Superintendencia Financiera de Colombia. Concepto No. 2005061070-00 (diciembre 9 de 2005).

Superintendencia Financiera de Colombia. Concepto No. 2006051752-001 (diciembre 22 de 2006).

Superintendencia Financiera de Colombia. Sentencia 2017-0823 (marzo 15 de 2018).

\section{d. Laudos Arbitrales}

Distral S.A. (EMA) General Electric Canada Inc.vs La Nacional Compañía de Seguros Generales de Colombia S.A. Árbitros: Jorge Vélez García, Juan Carlos Esguerra Portocarrero y Antonio José de Irisarri Restrepo. (16 de agosto de 1995). 
Alstom Brasil vs Compañía Suramericana Seguros S.A. (hoy Seguros Generales Suramericana S.A.) Árbitros: Carlos Esteban Jaramillo, Antonio Pabón (14 de septiembre de 2006).

Beneficencia del Valle del Cauca vs. La Previsora S.A. Árbitros: Carlos Esteban Jaramillo, Carlos Ignacio Jaramillo y José Fernando Torres (5 de marzo de 2009).

Favestrella S.A vs. La Previsora y Otros. Árbitros: Jorge Eduardo Narváez Bonnet, Saúl Florez Enciso, Javier Bonivento Jiménez (3 de febrero de 2010).

Proyectar Valores S.A. Comisionista de Bolsa en Liquidación Forzosa Administrativa vs Chubb de Colombia Compañía de Seguros S.A: y Chartis Seguros Colombia S.A. (al momento del laudo AIG Seguros Colombia S.A., hoy SBS Seguros Colombia S.A.). Árbitros: Carmenza Mejía Martínez, Juan Carlos Esguerra Portocarrero y Juan Manuel Díaz Granados. (4 de noviembre de 2014).

Instituto de Seguro Sociales - ISS (en liquidación) vs La Previsora S.A. Compañía de Seguros. Árbitros: Adriana López Martínez, Jorge Eduardo Narváez Bonnet, José Guillermo Peña González (8 de octubre de 2015). 